\title{
ARF6 Directs Axon Transport and Traffic of Integrins and Regulates Axon Growth in Adult DRG Neurons
}

\author{
Richard Eva, ${ }^{1}$ Sarah Crisp, ${ }^{1}$ Jamie R. K. Marland, ${ }^{1}$ Jim C. Norman, ${ }^{2}$ Venkateswarlu Kanamarlapudi, ${ }^{3}$ \\ Charles ffrench-Constant, ${ }^{4}$ and James W. Fawcett ${ }^{1}$ \\ ${ }^{1}$ Cambridge Centre for Brain Repair, Department of Clinical Neurosciences, University of Cambridge, Cambridge CB2 OPY, United Kingdom, ${ }^{2 B}$ eatson \\ Institute for Cancer Research, Bearsden, Glasgow G61 1BD, United Kingdom, ${ }^{3}$ Institute of Life Science, College of Medicine, Swansea University, Singleton \\ Park, Swansea SA2 8PP, United Kingdom, ${ }^{4}$ Medical Research Council Centre for Regenerative Medicine, Centre for Multiple Sclerosis Research, University \\ of Edinburgh, Queen's Medical Research Institute, Edinburgh EH16 4TJ, United Kingdom
}

Integrins are involved in axon growth and regeneration. Manipulation of integrins is a route to promoting axon regeneration and understanding regeneration failure in the CNS. Expression of $\alpha 9$ integrin promotes axon regeneration, so we have investigated $\alpha 9 \beta 1$ trafficking and transport in axons and at the growth cone. We have previously found that $\alpha 9$ and $\beta 1$ integrins traffic via Rab11-positive recycling endosomes in peripheral axons and growth cones. However, transport via Rab11 is slow, while rapid transport occurs in vesicles lacking Rab11. We have further studied $\alpha 9$ and $\beta 1$ integrin transport and traffic in adult rat dorsal root ganglion axons and PC12 cells. Integrins are in ARF6 vesicles during rapid axonal transport and during trafficking in the growth cone. We report that rapid axonal transport of these integrins and their trafficking at the cell surface is regulated by ARF6. ARF6 inactivation by expression of ACAP1 leads to increased recycling of $\beta 1$ integrins to the neuronal surface and to increased anterograde axonal transport. ARF6 activation by expression of the neuronal guanine nucleotide exchange factors, ARNO or EFA6, increases retrograde integrin transport in axons and increases integrin internalization. ARF6 inactivation increases integrin-mediated outgrowth, while activation decreases it. The coordinated changes in integrin transport and recycling resulting from ARF6 activation or inactivation are the probable mechanism behind this regulation of axon growth. Our data suggest a novel mechanism of integrin traffic and transport in peripheral axons, regulated by the activation state of ARF6, and suggest that ARF6 might be targeted to enhance integrin-dependent axon regeneration after injury.

\section{Introduction}

Integrins are a large family of transmembrane proteins that function as receptors for extracellular matrix molecules. They have functions in both the developing and mature nervous system, with roles in neurite outgrowth, synaptic plasticity, and peripheral nerve regeneration (Werner et al., 2000; Brakebusch and Fässler, 2005; Gardiner et al., 2005, 2007; Webb et al., 2007; Lin et al., 2008; Plantman et al., 2008; McGeachie et al., 2011; Myers and Gomez, 2011). Integrins exist as heterodimers, composed of an $\alpha$ - and a $\beta$-subunit, with the specificity for their ligands being governed by the combined properties of both subunits. In our studies on spinal cord injury, we have focused on the integrin $\alpha 9 \beta 1$, because it is a receptor for tenascin-C, a matrix protein that is present in the adult CNS and upregulated after injury (Tang et

Received March 22, 2012; revised May 8, 2012; accepted May 29, 2012.

Author contributions: R.E., J.C.N., C.f.-C., and J.W.F. designed research; R.E., S.C., and J.R.K.M. performed research; R.E. and V.K. contributed unpublished reagents/analytic tools; R.E. analyzed data; R.E. wrote the paper.

This work was supported by grants from Medical Research Council, The Henry Smith Charity, The Christopher and Dana Reeve Foundation, The John and Lucille van Geest Foundation, the EU Framework 7 Project Plasticise, the National Institutes for Health Research-Cambridge Biomedical Research Centre, and the Biotechnology and Biological Sciences Research Council. We thank Dr. Victor Hsu for the gift of the ARF6 and ACAP1 plasmid DNA, and Dr. Julie Donaldson for the gift of the EFA6 plasmid DNA.

Correspondence should be addressed to James Fawcett, Cambridge Centre for Brain Repair, Department of Clinical Neurosciences, University of Cambridge, Robinson Way, Cambridge CB2 OPY, UK. E-mail: jf108@cam.ac.uk.

DOI:10.1523/JNEUROSCI.1409-12.2012

Copyright $\odot 2012$ the authors $\quad 0270-6474 / 12 / 3210352-13 \$ 15.00 / 0$ al., 2003). We have reported that exogenous $\alpha 9 \beta 1$ expression can enhance sensory axon regeneration into the spinal cord (Andrews et al., 2009). However, as integrin transport is restricted in some CNS axons, we have also studied $\alpha 9 \beta 1$ trafficking. In a previous paper we demonstrated an integrin recycling pathway via Rab11-positive recycling endosomes, which can be manipulated to enhance axon growth (Eva et al., 2010). While much of the integrin in axons was found in Rab11-positive vesicles, we noted that integrin undergoing rapid long-range movement was not associated with Rab11. We hypothesized that the carrier for rapid transport might be ARF6. ARF6 is another GTPase present on recycling endosomes, and it is reported to function together with Rab11 in the recycling of integrins and during cytokinesis (Hickson et al., 2003; Powelka et al., 2004; Fielding et al., 2005; Inoue et al., 2008). ARF6 is present in neurons in the CNS where it is involved in axonal and dendritic development and dendritic spine morphology (Hernández-Deviez et al., 2002, 2004; Miyazaki et al., 2005; Choi et al., 2006), but there is no literature regarding its role in neuronal integrin traffic.

As in our previous work, we have investigated the trafficking of $\alpha 9$ and $\beta 1$ integrins in adult dorsal root ganglion (DRG) neurons and PC12 cells, and report that integrins traffic and transport in these cells via ARF6.

We have investigated the regulation of integrin transport and trafficking through manipulation of ARF6 activity using the overexpression of ACAP1, an ARF6 GTPase activating protein 
(GAP), and two neuronal ARF6 guanine nucleotide exchange factors (GEFs) EFA6 and ARNO. Inactivation of ARF6 by ACAP1 enhances axon growth, externalization of integrin, and anterograde integrin transport, while activation of ARF6 using EFA6 and ARNO reduces axon growth and increases integrin internalization and retrograde integrin transport. Our data therefore describe a novel role for ARF6 in the regulation of integrin traffic and transport in peripheral axons and suggest that ARF6 might be targeted to enhance integrin-dependent outgrowth during regeneration after injury.

\section{Materials and Methods}

DNA constructs. Integrin $\alpha 9$ enhanced green fluorescent protein (EGFP)-N3 was obtained from Addgene (plasmid 13600), deposited by Dean Sheppard (University of California, San Francisco, CA), and has been described previously (Eva et al., 2010). pXS-HA-ARF6 (Radhakrishna et al., 1996), pcDNA3.1-ACAP1-myc (Li et al., 2007b), and pFLAG-CMV2-ACAP1R448Q (Jackson et al., 2000) were all gifts from Dr. Victor Hsu (Department of Medicine, Harvard Medical School, Boston, MA). pcDNA3-ARF6-Q67L and pcDNA3-ARF6-T27N (Peters et al., 1995; Furman et al., 2002) were obtained from Addgene (plasmid 10835 and 10831, respectively) and deposited by Thomas Roberts/Richard Klausner (Harvard Medical School, Boston, MA). pFLAG-CMV6-EFA6 (Brown et al., 2001) was a gift from Dr. Julie Donaldson (National Heart Lung and Blood Institute, National Institutes of Health, Bethesda, MD). EFA6 cDNA was obtained by PCR amplification using pFLAG-CMV6-EFA6 as a template and was digested with EcoRI and SalI and cloned into the same sites of pEGFP-C1 (Clontech) to obtain pEGFPC1-EFA6. pEGFPC1-ARNO construct was described previously (Venkateswarlu et al., 1998). The ARNO cDNA released from pBTM116ARNO (Venkateswarlu, 2003) by EcoRI and SalI digestion was cloned into the same sites of pCMV-FLAG2B (Stratagene) to obtain pCMV-FLAG2BARNO. pSNAP-ARF6 was generated by cloning full-length human ARF6, amplified by PCR from pARF6-CFP (obtained from Addgene; plasmid 11382), and deposited by Joel Swanson into the pSNAPm vector (New England Biolabs) EcoR1 site.

Antibodies. Antibodies against ARF6 were obtained from Abcam: ab77581 was used for immunofluorescence and ab49931 was used for Western blotting. Directly conjugated Alexa Fluor 488 or 647 antimouse/rat CD29 (integrin $\beta 1$ ) antibody (clone HM $\beta 1-1$; BioLegend) was used for detecting $\beta 1$ integrin on fixed cells and also for live labeling and imaging. $\beta 1$ integrin was detected on Western blots using the antibody AB1952 (Millipore). AB1952 was also used for ELISA capture of biotinylated $\beta 1$ integrin for the internalization and recycling assays. Captured biotinylated $\beta 1$ integrin was detected with streptavidin-conjugated horseradish peroxidase (HRP) (Vector Laboratories). KDEL was detected with anti-KDEL clone 10C3 (Abcam), GM130 with polyclonal anti-GM130 (BD Biosciences Transduction Laboratories), and Rab11 with anti-Rab11 from Invitrogen (Zymed). $\beta$-actin was detected using the antibody AC-15 (Abcam). Hemagglutinin (HA) tag was detected with anti-HA clone 16B12 (Covance), FLAG epitope with Abcam ab182390, and myc with anti-myc clone 9E10 (Santa Cruz Biotechnology). $\alpha 9 \beta 1$ integrin function was blocked with anti- $\alpha 9 \beta 1$ clone Y9A2 (Abcam). Fluorescent secondary antibodies were Alexa conjugates from Invitrogen used at 1:800. HRP-conjugated secondary antibodies for Western blotting were from GE Healthcare.

Dissociated adult rat DRG cultures. Adult male Sprague Dawley rats were killed and DRGs were removed. DRGs were incubated with $0.1 \%$ collagenase in DMEM for $90 \mathrm{~min}$ at $37^{\circ} \mathrm{C}$ followed by $10 \mathrm{~min}$ in trypsin at $37^{\circ} \mathrm{C}$. DRGs were dissociated by trituration in a blunted glass pipette. Dissociated cells were then centrifuged through a layer of $15 \%$ bovine serum albumin (BSA), washed in DMEM, and cultured on $1 \mu \mathrm{g} / \mathrm{ml}$ laminin, on poly-D-lysine-coated acid-washed coverslips in DMEM supplemented with $10 \%$ fetal calf serum (Invitrogen), $1 \%$ penicillin/streptomycin, and $30 \mathrm{ng} / \mathrm{ml}$ nerve growth factor (NGF).

PC12 cell culture. Low passage number PC12 cells were cultured as previously described (Eva et al., 2010), routinely grown in RPMI 1640 media (Sigma-Aldrich), and supplemented with $10 \%$ batch-tested French fetal bovine serum (Biosera), 1\% penicillin/streptomycin, and 2
mM L-glutamine on flasks coated with type IV collagen (Sigma-Aldrich). For differentiation to a neuronal phenotype, PC12 cells were primed at low density in the usual culture media supplemented with $50 \mathrm{ng} / \mathrm{ml} \mathrm{NGF}$ (Sigma-Aldrich) for $10 \mathrm{~d}$ and stored at $-80^{\circ} \mathrm{C}$ or used immediately. Primed PC12 cells were differentiated in the usual media supplemented with $50 \mathrm{ng} / \mathrm{ml} \mathrm{NGF}$ (Sigma-Aldrich) and analyzed after $2 \mathrm{~d}$. Cells were therefore analyzed a total of $12 \mathrm{~d}$ after treatment with NGF. PC12 cells stably expressing $\alpha 9$ integrin have been described previously (Eva et al., 2010), and were grown in the same conditions as wild-type (wt) PC12 cells, except when used for the $\alpha 9$ integrin-specific neurite outgrowth assay. PC12 cells stably expressing ARF6-SNAP were generated by electroporation followed by selection with $400 \mu \mathrm{g} / \mathrm{ml}$ neomycin (G418; Invitrogen). Nonclonal lines were generated, as the ARF6-SNAP vector contains the neomycin resistance gene on an internal ribosomal entry site cassette.

Analysis of $\alpha 9$ integrin-dependent neurite outgrowth. To analyze $\alpha 9$ integrin-dependent neurite outgrowth, PC12 cells stably expressing $\alpha 9$ integrin were grown on a substrate of tenascin, as described previously (Eva et al., 2010). PC12 cells were primed as described above, and after $10 \mathrm{~d}$ in the presence of NGF, cells were trypsinized and electroporated with either DNA constructs or mock transfected as a control. Cells were then plated onto 24 -well culture plates coated with $5 \mu \mathrm{g} / \mathrm{ml}$ tenascin (Millipore) and grown for two $2 \mathrm{~d}$ in the usual differentiation media but without antibiotics. All cells were additionally cultured in the presence of the $\alpha 9 \beta 1$ blocking antibody Y9A2 (Abcam) at 1:300, a concentration we previously determined as generating a partial block of function. Cells were then fixed and labeled to identify the epitope tag and analyzed in situ either by phase contrast microscopy or by virtue of the fluorescent signal. Neurite outgrowth analysis was performed $2 \mathrm{~d}$ after plating in differentiation media (a total of $12 \mathrm{~d}$ in the presence of NGF). Neurite outgrowth was analyzed using a Leica DM6000 microscope and Leica LAS AF software to measure the length of neurites in micrometers. The longest neurites of 50 cells were measured per condition. Four wells were analyzed per experiment, and three experiments were performed. GraphPad Prism was used for statistical analysis of data.

Transfection of dissociated adult DRG neurons for analysis of axon growth. DRG neurons were removed and dissociated as described above. Cells were transfected with plasmid DNA encoding GFP- or epitopetagged constructs or transfected with plasmid DNA encoding GFP alone as a control. Transfection was achieved using a Microporator (Invitrogen). Approximately $1 \times 10^{5}$ cells were transfected per reaction in a volume of $10 \mu$ l. Transfected cells were plated and cultured as described above, but without antibiotics. Axon length was analyzed after $48 \mathrm{~h}$ in culture. Cells were fixed and labeled and viewed with a Leica DM6000 microscope, and Leica LAS AF software was used to trace and measure the length of axons in micrometers. The longest axon of all transfected cells was measured for each experiment. Between 35 and 98 neurons were analyzed per condition per experiment. On average, 60 neurons were analyzed per condition. GraphPad Prism was used for statistical analysis of data.

Transfection of dissociated adult DRG neurons for live imaging experiments. Adult DRG neurons were dissociated and cultured as described above on glass-bottom imaging dishes (MatTek) for $24 \mathrm{~h}$ before being transfected using a Cellaxess in-dish electroporator (Cellectricon). In this way, neurons had already extended axons before they expressed the transfected constructs. Cells were transfected with $\alpha 9$ integrin-GFP, either alone or cotransfected with the indicated epitope-tagged constructs. In preliminary experiments performed to test the cotransfection efficiency, $100 \%$ of $\alpha 9$-GFP-expressing neurons also expressed the cotransfected epitope-tagged construct (determined after fixing and antibody labeling).

Analysis of ARF6-SNAP vesicle dynamics in neurites. To analyze the dynamics of ARF6 vesicles within neurites, PC12 cells stably expressing ARF6-SNAP were primed and differentiated for a total of $12 \mathrm{~d}$ as described above, so that they had a mature neuronal phenotype, with lengthy processes. These were grown on collagen-coated glass-bottom imaging dishes (MatTek), and loaded with SNAP-cell TMR-Star dye (New England Biolabs) (which has an emission peak of $580 \mathrm{~nm}$ ), to identify ARF6-positive structures. Control experiments were also per- 
formed using untransfected cells or transfected cells treated with the SNAP blocking reagent (NEB) to ensure that the dye was binding specifically to ARF6-SNAP. Cells were labeled for $30 \mathrm{~min}$, washed three times, and left for $30 \mathrm{~min}$ to allow unbound dye to leave the cells before washing again. To identify ARF6 vesicles containing endogenous $\beta 1$ integrins, cells were additionally labeled with anti $\beta 1-488$ (BioLegend) for $1 \mathrm{~h}$ and washed three times before imaging. Cells were imaged using spinning disk confocal microscopy, with an Olympus IX70 microscope, a Hamamatsu EM-CCD Image-EM camera, and a PerkinElmer UltraVIEW scanner, controlled with MetaMorph software. Images were acquired every $3 \mathrm{~s}$. Kymographs were generated using MetaMorph software. ARF6 vesicle dynamics were quantified using the methods we have previously described for analyzing Rab11 or $\alpha 9$-GFP vesicle dynamics (Eva et al., 2010). Instantaneous velocity was calculated using MetaMorph software to measure the distance moved by a vesicle between two consecutive frames. Vesicles were tracked for their visible lifetime, and the maximum distance moved between two frames was measured and used to calculate instantaneous speed. Both anterograde and retrograde vesicles were included for analysis (as for Rab11 or $\alpha 9$-GFP previously). Bidirectional and immobile vesicles were not included for quantification, counting moving vesicles as anything moving faster than $0.5 \mu \mathrm{m} / \mathrm{s}$. The distance covered by vesicles over time was measured as the maximum net distance a vesicle moved $>10$ frames (30 s). Thirty-nine neurite lengths containing 318 vesicles were analyzed from a total of five experiments. Velocities were binned into $0.2 \mu \mathrm{m} / \mathrm{s}$, and distance was binned into $1 \mu \mathrm{m}$.

$D R G$ live imaging and analysis of axon transport. DRG neurons expressing $\alpha$-GFP (either alone or in the presence of an epitope-tagged ARF6 regulatory protein, as indicated) were imaged in glass-bottom dishes using live spinning disk confocal microscopy, as described above, and analyzed using MetaMorph software. Axonal vesicles were analyzed to determine the proportion of mobile and immobile vesicles and the proportion of mobile vesicles moving anterograde, retrograde, or bidirectionally. Vesicles with a total movement of $<2 \mu \mathrm{m}$ during their visible lifetimes were classed as immobile. Vesicles moving in both directions but with net movement of $<2 \mu \mathrm{m}$ (during their visible lifetimes) were classed as bidirectional, even though total movement may have been larger. Vesicles with net movements $>2 \mu \mathrm{m}$ in either direction (by the end of their visible lifetimes) were classed as anterograde or retrograde accordingly.

Instantaneous velocity of anterograde and retrograde vesicles was quantified as described above. Average velocity was also measured. This was quantified as the net distance moved by a vesicle during its visible lifetime, divided by the amount of time for which it was tracked. One hundred fifty-two neurite lengths containing 2325 vesicles were analyzed in total, from three individual experiments. One experiment used DRG cultures generated from a single animal, plated onto five imaging dishes for transfection with the various indicated DNA constructs, so that each condition could be investigated in neurons taken from the same animal. Data were analyzed using GraphPad Prism.

Microscopy. Three microscopes were used in this study, as has been indicated. Laser scanning confocal microscopy was performed using a Leica DMI4000B microscope, with laser scanning and detection achieved by a Leica TCS SPE confocal system controlled with Leica LAS AF software. Standard fluorescent microscopy was performed using a Leica AF7000 with a Hamamatsu EM CCD C9100 camera and Leica LAS AF software. Live-cell imaging was performed with an Olympus IX70 microscope using a Hamamatsu EM-CCD Image-Em camera and a PerkinElmer UltraVIEW scanner for spinning disk confocal microscopy controlled with MetaMorph software.

Subcellular fractionation. This was performed as previously described (Eva et al., 2010). Briefly, PC12 cells were differentiated for $12 \mathrm{~d}$. Cells were homogenized through a 21 gauge needle in detergent-free homogenization buffer ( $250 \mathrm{~mm}$ sucrose, $3 \mathrm{~mm}$ imidazole, $1 \mathrm{~mm}$ EDTA and protease inhibitors, $\mathrm{pH}$ 7.4) and a postnuclear supernatant (PNS) was generated. The PNS was adjusted to $40.6 \%$ sucrose in $3 \mathrm{~mm}$ imidazole, 1 mM EDTA, pH 7.4. This was then loaded on the bottom of an ultraclear SW55 TI centrifuge tube (Beckman Coulter) and overlaid sequentially with $1.5 \mathrm{ml}$ of $35 \%$ sucrose and $1 \mathrm{ml}$ of $25 \%$ sucrose, and filled to the top with $1.5 \mathrm{ml}$ homogenization buffer. This was centrifuged at $130,000 \mathrm{~g}$ for
$1.5 \mathrm{~h}$ at $4^{\circ} \mathrm{C}$ using an SW55 TI rotor (Beckman Coulter). After centrifugation, gradients were collected from top (fraction 1) to bottom (fraction 8 ). Protein concentration at each fraction was determined using BCA protein assay (Pierce). Equal volumes from each fraction were analyzed by Western blotting.

$\beta 1$ integrin internalization and recycling assays. This method was established previously (Roberts et al., 2001; Pellinen et al., 2006; Arjonen et al., 2012). First, two $\beta 1$ integrin antibodies, clone HM $\beta 1-1$ (BioLegend) and AB1952 (Millipore), were tested for capture ELISA specificity by biotinylating the surface of cells, lysing them, and performing immunoprecipitation with either antibody, and running the lysate on a Western blot, for detection by streptavidin-HRP. Both antibodies generated a specific $\beta 1$ integrin band. These antibodies were then titrated for the ELISA assay to determine optimum antibody concentration, and AB1952 was chosen for use at 1:200. ELISA plates were coated with this antibody overnight (1:200; $50 \mu \mathrm{l}$ per well in $0.05 \mathrm{M} \mathrm{Na}_{2} \mathrm{CO}_{3} \mathrm{pH} 9.6$ at $4^{\circ} \mathrm{C}$ ), and blocked for $1 \mathrm{~h}$ (5\% BSA in PBS with $0.1 \%$ Tween 20) before loading with lysate. For the internalization assay, PC12 cells were differentiated for $10 \mathrm{~d}$ and electroporated with ARF6 regulatory proteins as indicated, or mock transfected as a control, and grown in standard differentiation media in 6 $\mathrm{cm}$ culture plates for $2 \mathrm{~d}$ to allow maximum expression of the transfected constructs. The cells were placed on ice and washed with ice-cold PBS. The cell surface was then labeled with $380 \mu \mathrm{g} / \mathrm{ml}$ EZ-link sulfo-NHS-SSbiotin (Thermo Scientific) in ice-cold PBS for $30127 \mathrm{~min}$ at $4^{\circ} \mathrm{C}$, and unbound biotin was removed with two washes of ice-cold PBS. Prewarmed media was then added to cells, and they were placed at $37^{\circ} \mathrm{C}$ for $30 \mathrm{~min}$, to allow internalization to occur. Cells were then placed immediately on ice and washed with cold PBS. Biotin remaining at the cell surface after internalization was removed with $60 \mathrm{~mm}$ sodium 2-mercaptoethanesulfonate (MesNa; Sigma) in reduction buffer ( $50 \mathrm{~mm}$ Tris $\mathrm{pH}$ 8.6, $100 \mathrm{~mm} \mathrm{NaCl}$ ) for 30127 min on a rocker at $4^{\circ} \mathrm{C}$ followed by quenching with $100 \mathrm{~mm}$ iodoacetamide (Sigma) for $12710 \mathrm{~min}$, leaving only internalized biotin inside the cells. This step was omitted from one dish to allow for quantification of total biotin load, so that the relative amounts of biotinylated internalized integrins were normalized to the biotin signal of all labeled integrins. Cells were then lysed in radioimmunoprecipitation assay buffer, cleared by centrifugation, and the lysate loaded on to the precoated ELISA plate for $2 \mathrm{~h}$. Plates were then washed, labeled with secondary streptavidin HRP (Vector Laboratories) for $1 \mathrm{~h}$, and visualized with $o$-phenylenediamine dihydrochloride (OPD; Thermo Scientific) according to manufacturer's instructions. Absorbance was then measured at $490 \mathrm{~nm}$. For the recycling assay, biotinylated cells were incubated similarly at $37^{\circ} \mathrm{C}$ for $30 \mathrm{~min}$ to allow the internalization of biotinlabeled integrins, and surface biotin was again cleaved with $60 \mathrm{~mm}$ MesNa on ice and quenched with $100 \mathrm{~mm}$ iodoacetamide (Sigma) for $10 \mathrm{~min}$ on ice. One plate per condition was then kept on ice (time 0 ), while others were placed in prewarmed media and incubated at $37^{\circ} \mathrm{C}$ to allow recycling to occur. Dishes were then moved back to $4^{\circ} \mathrm{C}$ after 5,10 , or $15 \mathrm{~min}$ at $37^{\circ} \mathrm{C}$, and surface biotin was removed with $60 \mathrm{~mm}$ MesNa on ice. Cells were then lysed and biotinylated integrin quantified by ELISA as for internalization. In this way, total biotinylated internalized integrin was quantified at time 0 , and the fraction remaining inside measured at the various time points. From this value, the amount of recycled integrin could be expressed as a percentage of total internalized integrin.

\section{Results}

Our experiments focus on $\alpha 9 \beta 1$ integrin, as in our previous work, because of its relevance to axon regeneration in the spinal cord. We use two models, adult rat DRG axons and PC12 cells. PC12 cells have been used for experiments on integrin internalization and recycling, which cannot be performed in primary DRG cultures, while most axon growth and axonal transport assays have been performed in adult DRG neurons. We obtained congruent results from the two cell types. Using these cell types it is possible to perform integrin-dependent growth assays, because neither DRG axons nor PC12 cell neurites will grow on tenascin surfaces unless they are transfected with $\alpha 9$. Our experiments focus on both $\beta 1$ and $\alpha 9$ integrins; the $\beta 1$ subunit is expressed by both cell types, allowing for more complex experiments on an 
Table 1. Summary of ARF6-related constructs used for investigating the role of ARF6 in integrin-dependent neurite outgrowth and integrin transport, internalization and recycling

\begin{tabular}{ll}
\hline ARF6 wild-type & Tagged with a SNAP tag or HA for recognition \\
\hline ARF6-T27N & Dominant-negative ARF6 \\
ARF6-067L & Constitutively active ARF6 \\
ACAP1 & ARF6 GAP, increases ARF6-GDP (inactivation) \\
ACAP1-R4480 & Also acts as a coat protein \\
EFA6 & Dominant-negative GAP-dead mutant \\
ARN0 & Still functions as a coat protein \\
\hline
\end{tabular}

$\mathrm{HA}$, hemagglutinin.

endogenous integrin. To study the role of ARF6 in integrin transport, internalization, and recycling we have used a number of ARF6-related constructs. To aid comprehension of the experiments, these constructs have been summarized in Table 1.

\section{Does ARF6 colocalize with integrin in axons and growth cones?}

We first asked whether endogenous ARF6 colocalized with integrins in the axons and growth cones of adult DRG neurons, focusing on endogenous $\beta 1$ integrin while performing additional experiments with PC1 2 cells stably expressing $\alpha 9$ integrin. Using $\beta 1$ integrin and ARF6 immunocytochemistry, we found partial overlap between the two proteins at the growth cones and axons of adult DRGs in distinct regions of the growth cone (Fig. $1 A$, triangle) and in vesicular structures (arrows). To confirm this result we used epitope-tagged wt and mutant ARF6 constructs, which are well established tools used for investigating ARF6 distribution (Donaldson, 2003; Gillingham and Munro, 2007). Adult DRG neurons were transfected with HA-tagged wt ARF6, dominant inactive ARF6 (ARF6-T27N), or constitutively active ARF6-Q67L, all of which partially colocalized with $\beta 1$ integrin at the growth cone (Fig. $1 B-D$ ). We found overlap between wtARF6-HA and $\beta 1$ integrin in filopodia (Fig. $1 B$, dotted lines), as well as in distinct structures such as the curved tubular structure magnified in Figure $1 B$, and in vesicles (arrows). Dominantnegative ARF6-T27N expression resulted in prominent $\beta 1$ integrin fluorescence at the growth cone periphery where the two proteins colocalized (Fig. 1C, dotted lines), and we also found colocalization in vesicular structures inside the growth cone (arrows). Expression of constitutively active ARF6-Q67L is known to cause enlarged endosomal structures containing ARF6regulated membrane constituents (Brown et al., 2001; Aikawa and Martin, 2003; Naslavsky et al., 2003; Sannerud et al., 2011). We found that ARF6-Q67L expression generated enlarged endosomal structures that were positive for both ARF6-Q67L and $\beta 1$ integrin throughout adult DRG neurons, including at the cell body (data not shown) and growth cone where vacuolar structures were found aggregating in the central domain (Fig. $1 D$, oval region). These enlarged structures were also present in the axons of ARF6-Q67L transfected cells (Fig. $1 E$ ), but not in the axons of wt or ARF6-T27N transfected cells. Colocalization was also observed in vesicular structures of more normal appearance (Fig. $1 D$, arrow). These experiments were also performed in differentiated PC12 cells (both wt and stably expressing $\alpha 9$ ) where we found similar overlap of both $\beta 1$ and $\alpha 9$ integrin with ARF6 (data not shown). We also confirmed that endogenous ARF6 is present in an endosomal fraction, using vesicles purified from differentiated PC12 cells by a protocol that we have previously used to investigate integrin and Rab11 distribution (Eva et al., 2010).
Subcellular fractionation was used to divide vesicular structures into eight pools, fractions 4 and 5 corresponding to endosomes. We found that ARF6, $\beta 1$ integrins, and Rab11 were all enriched in these endosomal fractions (Fig. $1 F$ ). Together these data suggest that integrins are present in ARF6 vesicles, suggesting the possibility that ARF6 is involved in the trafficking of $\beta 1$ integrins in axons and growth cones.

\section{Are integrins rapidly transported over long distances via ARF6-positive endosomes?}

We previously found that a population of vesicles containing $\alpha 9$ integrin are transported rapidly over long distances along neurites, exiting the Rab11 compartment as they begin rapid movement (Eva et al., 2010). We wondered if these fast-moving structures are associated with ARF6 during their periods of rapid movement. To address this we tried live imaging of ARF6-GFP, but found that it localized unexpectedly to large amorphous blobs. Other researchers have found that ARF6-GFP does not always localize as expected (Hall et al., 2008), so we turned to a SNAP tag as an alternative. This is a nonfluorescent monomeric protein tag that can be visualized in live cells with membranepermeable dyes that bind irreversibly and covalently to the tag. We first generated PC12 cells stably expressing ARF6-SNAP then live-labeled the cells with a red fluorescent dye, followed by application of green anti- $\beta 1$ integrin-Alexa 488 , which internalizes attached to $\beta 1$ integrin. ARF6-SNAP localized to the cell membrane and vesicular structures, and internalized $\beta 1-488$ colocalized with these vesicles (Fig. $2 A$ ). We confirmed the specificity of the dye by using a nonfluorescent variant to block the tag before addition of the dye (data not shown). We then investigated the dynamics of ARF6-SNAP in the neurites of differentiated PC12 cells using spinning disk confocal microscopy, and quantified the instantaneous velocity and distance traveled by ARF6-SNAP vesicles. We found that the majority of ARF6 vesicles were fast moving, traveling at a velocity of $1-2 \mu \mathrm{m} / \mathrm{s}$ with the majority of vesicles covering $2-12 \mu \mathrm{m} / 30 \mathrm{~s}$ (Fig. $2 \mathrm{~B}$ ). This is a similar velocity to the population of rapidly moving Rab11-negative $\alpha 9$-GFP vesicles, which we previously found to move at a velocity between 1 and $3 \mu \mathrm{m} / \mathrm{s}$, covering distances of $0.2 \mu \mathrm{m} / 30 \mathrm{~s}-10.4 \mu \mathrm{m} / 30 \mathrm{~s}$ (Eva et al., 2010). We asked whether endogenous integrins were transported in these vesicles. To address this, we live labeled the cells with anti $\beta 1$-Alexa 488 , which allows visualization of cell-surface integrins as well as internalized integrins in vesicular structures. The dye-labeled ARF6-SNAP bleached rapidly, making these experiments technically challenging; however, we found ARF6SNAP and $\beta 1-488$ moving in concert in rapidly moving vesicles (Fig. 2C,D, kymograph). We also observed ARF6-SNAP and $\alpha 9$ GFP moving similarly anterogradely along neurites (data not shown). These data demonstrate that ARF6 moves rapidly long distances in neurites, colocalizing with $\alpha 9 \beta 1$ integrin during rapid transport toward the growth cone.

\section{Can ARF6 expression and activity be modulated to enhance integrin-dependent neurite outgrowth?}

Our main aim is to enhance integrin-dependent axon regeneration after injury, so we next examined whether we could manipulate ARF6 expression and activity to enhance integrin-dependent axon growth. To address this, we used the $\alpha 9$ integrin specific outgrowth assay that we have described previously (Eva et al., 2010), in which NGF-stimulated PC12 cells will only grow processes on a substrate of tenascin if they express $\alpha 9$ integrin. PC12 cells stably expressing $\alpha 9$ were plated onto tenascin-C. To confirm the role of $\alpha 9$ in process outgrowth some cultures were treated with an $\alpha 9$ blocking antibody 
at a concentration that approximately halves outgrowth length (Fig. 3). We manipulated ARF6 activity using either an ARF6 GAP (inactivator) or GEF (activator), or by overexpressing wt ARF6. This approach mimics the control of ARF6 in vivo (as it has very low intrinsic GTPase activity, and almost totally relies on its GEFs and GAPs for control of its function) (Gillingham and Munro, 2007). Manipulation of ARF6 function with GAPs and GEFs is more physiological and less forceful than using ARF6 constructs locked in either the active GTP-bound form or inactive GDP-bound form (since ARF6 regulates many cellular functions by cycling between these two states) (Brown et al., 2001; Donaldson, 2003). Overexpression of ARF6 did not significantly affect process outgrowth (Fig. $3 A, B ; p>0.05)$. ACAP1 is an ARF6 GAP that has been reported to mediate $\beta 1$ integrin recycling in non-neuronal cells, acting either through its ARF6 GAP activity or additionally by acting as a coat protein (Jackson et al., 2000; Dai et al., 2004; Li et al., 2005, 2007b). Overexpression of ACAP1 substantially increased outgrowth (from 315 to $426 \mu \mathrm{m}$ ), while expression of GAP dead ACAP1 R448Q (a mutant ACAP1 that has no GAP activity but still functions as a coat protein) reduced outgrowth (to 278 $\mu \mathrm{m})$. In both cases, outgrowth was further reduced in the presence of the blocking antibody. This suggests that ACAP1 promotes integrin-dependent outgrowth, functioning through its ARF6 GAP activity and not by its function as a coat protein. We next investigated the effects of activating ARF6 using two ARF6 GEFs that are expressed in neurons, EFA6 (Sakagami, 2008) and ARNO (Hernández-Deviez et al., 2002, 2004, 2007; Hernández-Deviez and Wilson, 2005). EFA6 has ARF6-specific GEF activity (Franco et al., 1999; Macia et al., 2001), while ARNO is reported to have some ARF1 GEF activity in vitro, but is considered to be principally an ARF6 GEF (Frank et al., 1998; Venkateswarlu and Cullen, 2000; Macia et al., 2001; Gillingham and Munro, 2007; Hofmann et al., 2007). Expression of either ARNO or EFA6 resulted in a substantial inhibition of neurite outgrowth (to 143 and $207 \mu \mathrm{m}$, respectively), which was further reduced in the presence of the blocking antibody (Fig. $3 A, B$ ). These data show that ARF6 GEFs inhibit integrin-dependent neurite outgrowth, in contrast to the ARF6 GAP ACAP1, which enhances it.

Does modulation of ARF6 activity affect axon growth from adult DRG neurons?

Having demonstrated an effect of ARF6 modulation on integrindependent outgrowth by PC12 cells, we asked whether axon

B

C

D

$\mathbf{E}$
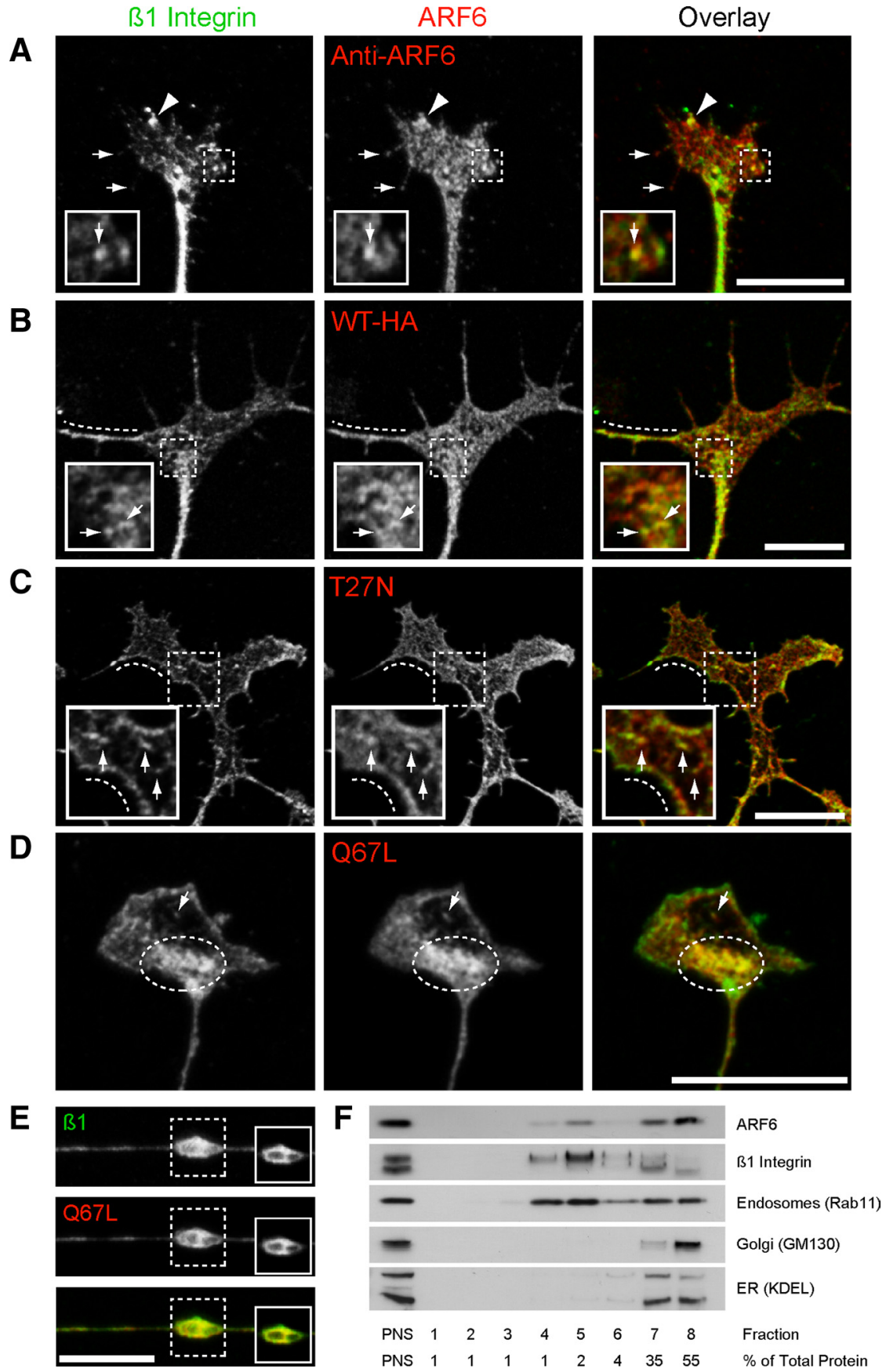

Figure 1. ARF6 regulates $\beta 1$ integrin localization in DRG axons and growth cones. Images are axons and growth cones of adult DRG neurons. ARF6 and $\beta 1$ integrins partly colocalize in distinct regions (triangle) and vesicular structures (arrows) ( $\boldsymbol{A}$, maximum projection and single confocal section inset). Overlap is also present after expression of wt ARF6-HA in growth cone vesicles ( $\boldsymbol{B}$, arrows; inset is a single confocal section) and filopodia ( $\boldsymbol{B}$, dotted lines). Expression of dominant-negative ARF6 T27N leads to prominent $\beta 1$ integrin localization at the growth cone periphery, where the two proteins colocalize ( $\boldsymbol{C}$, dotted lines). Colocalization is also evident in vesicles ( $\boldsymbol{C}$, arrows; inset is a single confocal section). Expression of constitutively active ARF6 Q67L results in accumulation of ARF6 in swollen intracellular structures within the growth cone, which also label for $\beta 1$ integrin ( $\boldsymbol{D}$, circled), and colocalization is also apparent at vesicular structures of more usual size ( $\boldsymbol{D}$, arrows). Swollen vesicles containing ARF6 and $\beta 1$ integrin were also present in DRG axons ( $\boldsymbol{E}$, inset is a single confocal section). Subcellular fractionation confirmed that ARF6 is enriched in the endosomal fraction (fraction 5) in maturely differentiated PC12 cells, as is $\beta 1$ integrin and Rab11 (F). Scale bars: 10 $\mu \mathrm{m} . \boldsymbol{A}-\boldsymbol{C}$ and $\boldsymbol{E}$ are maximum projections with a single confocal slice magnified in the inset. $\boldsymbol{D}$ is a single confocal section. growth from adult DRG neurons could also be enhanced. We therefore transfected dissociated DRG neurons, before plating on laminin with ACAP1, ACAP1 R448Q, ARNO, EFA6, or GFP as a control, and measured axon length after $2 \mathrm{~d}$ in culture. We found that ACAP1 expression increased axon length compared with 

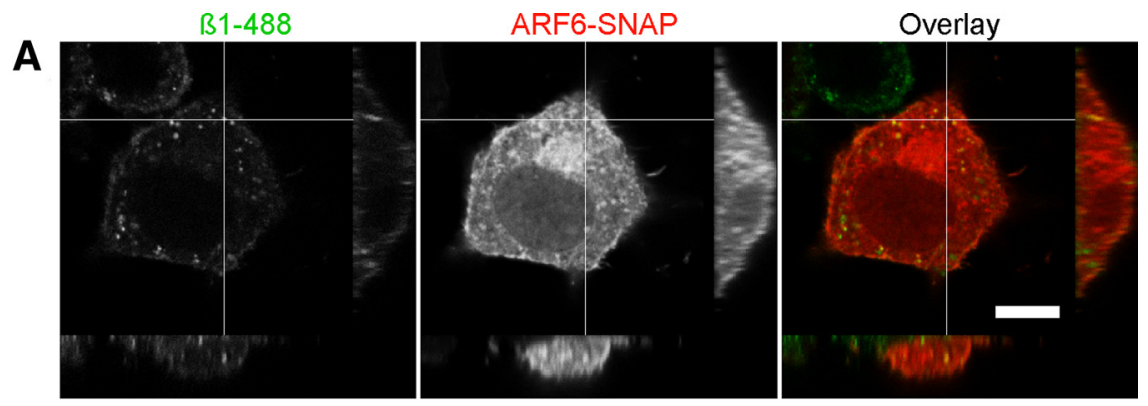

B
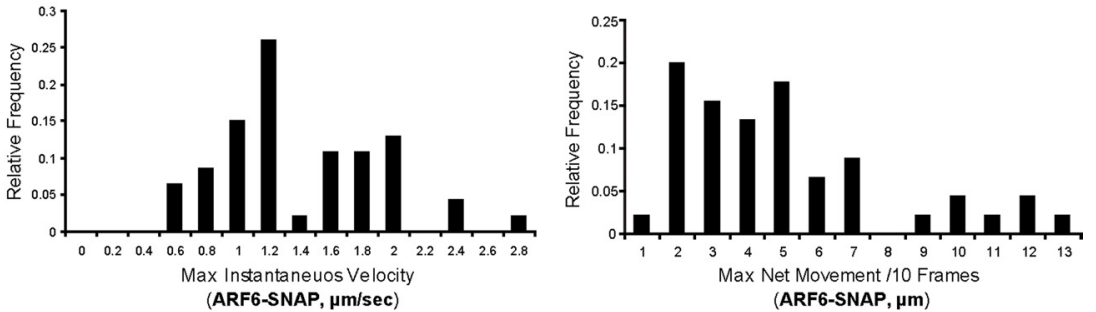

C
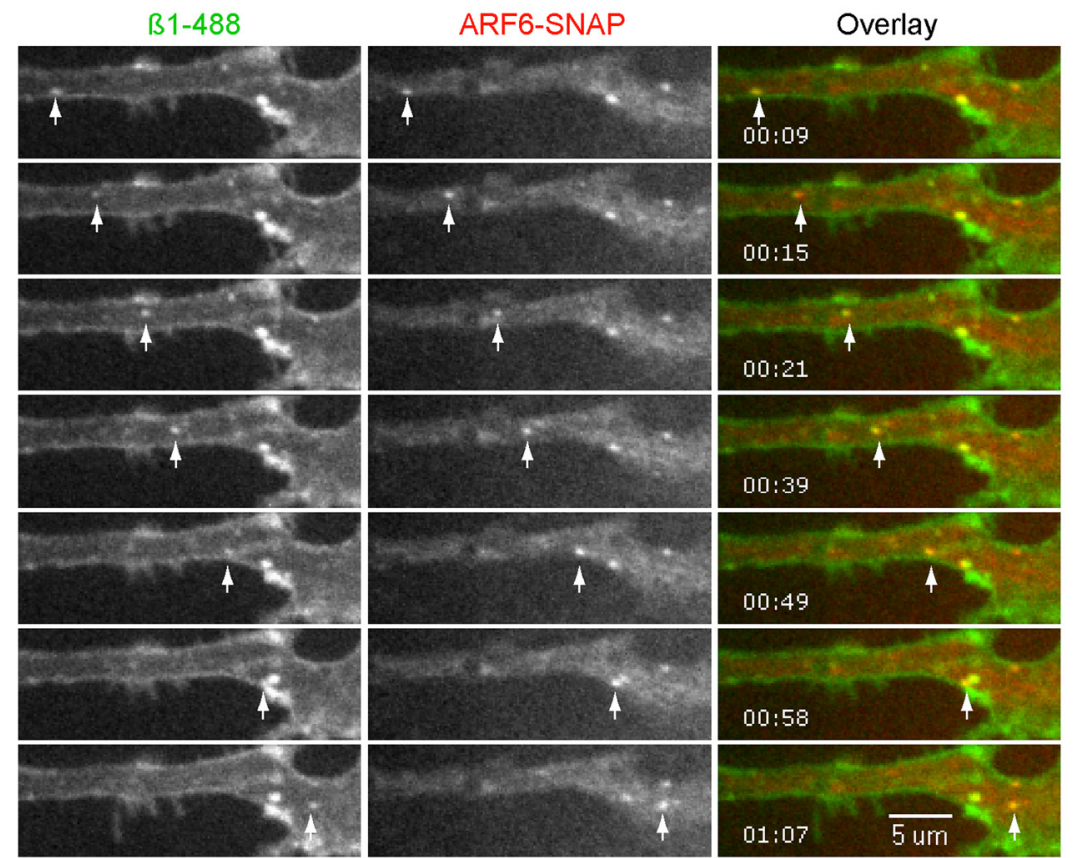

D

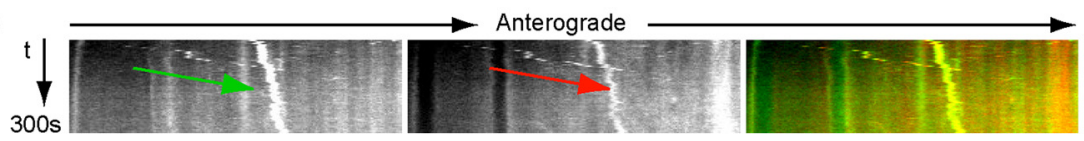

Figure 2. ARF6 vesicles are transported rapidly and contain $\beta 1$ integrins. SNAP-tagged ARF6 (red) colocalizes with internalized $\beta 1$ integrins (green) in PC12 cells live labeled with anti- $\beta 1-488$, and subsequently fixed and imaged by confocal microscopy $(\boldsymbol{A})$. Images shown are orthogonal views of a z-stack indicating vesicular colocalization, Scale bar, $10 \mu \mathrm{m}$. Spinning disk confocal microscopy was used to image maturely differentiated PC12 cells stably expressing ARF6-SNAP, and vesicle dynamics were quantified by tracking individual vesicles in neurites $(\boldsymbol{B})$. Vesicles were tracked for their visible lifetime and the instantaneous velocity was calculated from the maximum distance moved by a vesicle between two frames $(3 \mathrm{~s})$. Maximum net movement over 10 frames is a measure of the furthest a vesicle traveled from its origin over $30 \mathrm{~s}$. Anterograde and retrograde movements were included in the analysis. ARF6-SNAP movement is rapid and occurs over long distances. Differentiated PC12 cells stably expressing ARF6-SNAP were live labeled with anti- $\beta 1-488$ and imaged by spinning disk confocal microscopy. ARF6-SNAP vesicles dual labeled for $\beta 1$ integrin were observed moving anterogradely and retrogradely, and are shown here arriving at the growth cone (C). Arrows indicate a two-colored vesicle moving anterogradely. The rapid movement of this ARF6/ $\beta 1$ integrin-positive vesicle is indicated by the gentle slope displayed on a kymograph ( $\boldsymbol{D}$, arrows), which also displays a very slow moving structure (the very steep yellow line).

GFP-expressing controls (from 415 to $526 \mu \mathrm{m}$ ), and that EFA6 and ARNO both substantially inhibited axon growth (243 and $227 \mu \mathrm{m}$, respectively). EFA6-transfected cells had two phenotypes: one with short axons with a normal morphology, and one with abnormal neurite stubs that appeared bunched and branchy; however, there were no statistical differences in the number of neurites or branch points of these or any other axons compared with control cells.

Expression of ACAP1 R448Q also led to a reduction in axon length, but to a lesser extent (342 $\mu \mathrm{m})$ (Fig. 4). This suggests that ACAP1 overexpression enhances axon growth, via a mechanism that includes its GAP activity. These findings are similar to the results of our PC12 $\alpha 9$ integrin-dependent outgrowth assay, and suggest that ARF6 is involved in regulating axon growth in sensory neurons, at least in part, through an integrin-related effect.

Does modulation of ARF6 activity affect endocytosis or recycling of $\boldsymbol{\beta} 1$ integrins?

We wanted to establish if the effects on integrin-dependent outgrowth caused by ARF6 manipulation were associated with altered trafficking of integrins. ARF6 is involved in a number of trafficking processes, including internalization of membrane proteins from the cell surface (Naslavsky et al., 2004; Dunphy et al., 2006; Gong et al., 2007; Lavezzari and Roche, 2007), recycling of membrane proteins (Radhakrishna et al., 1996; Powelka et al., 2004; Barral et al., 2008; Yu et al., 2011), and transport along microtubules (Caplan et al., 2002; Kanamarlapudi, 2005; Balasubramanian et al., 2007; Montagnac et al., 2009, 2011). To address these issues we quantified the effects of increasing or decreasing ARF6 activation by overexpressing ACAP1, EFA6, or ARNO on integrin internalization and recycling. Here, $\beta 1$ integrin was investigated as it is expressed endogenously, allowing for results that would not be affected by overexpression of an integrin. To quantify $\beta 1$ integrin internalization we used an established capture-ELISA protocol (Roberts et al., 2001; Pellinen et al., 2006; Arjonen et al., 2012). Briefly, this involves biotinylation of the cell surface at $4^{\circ} \mathrm{C}$, followed by $30 \mathrm{~min}$ incubation at $37^{\circ} \mathrm{C}$, to restart trafficking and allow intracellular accumulation of biotinylated surface integrins. Cell-surface biotin is then removed at $4^{\circ} \mathrm{C}$ using a reduction buffer, so that only internalized biotin remains. The control is cells from which surface biotin has not been cleaved so that internalized biotinylated integrin can be expressed as a percentage of total biotinylated integrin. Lysed cell contents are assayed for biotinylated integrin using ELISA plates coated with $\beta 1$ integrin antibodies. 
We used the capture ELISA on maturely differentiated PC12 cells that had been transiently transfected to overexpress the ARF6 regulatory proteins and mock transfected controls. These cells exhibit large neuronal cell bodies and well established neurites and growth cones (Fig. 5D). Cells were transfected with the same amount of DNA, and all the constructs were under the control of the same promoter. We estimated that they were expressing similar amounts of protein by performing Western blots on the lysates of transfected cells (Fig. 5C). We also quantified the transfection efficiency of the cells transfected with GFP-tagged constructs before each experiment. The efficiency was typically $70-80 \%$. We found that inactivation of ARF6 with the ARF GAP ACAP1 had no effect on the amount of $\beta 1$ integrin that was internalized from the cell surface $>30 \mathrm{~min}$ (Fig. $5 A, p>$ 0.05), but that overexpression of the GAP dead ACAP1-R448Q mutant resulted in a significant increase in internalized $\beta 1$ integrin compared with mock transfected controls (from 21 to $31 \%, p<0.01$ ). Activation of ARF6 by overexpression of either of the ARF GEFs, EFA6 or ARNO, also greatly increased integrin endocytosis (37 and 38\%, respectively, $p<0.001$; Fig. $5 A)$. This would suggest that ACAP1 $\mathrm{R} 448 \mathrm{Q}$ is acting as a dominant-negative ACAP1 with respect to $\beta 1$ integrin internalization (behaving similarly to two ARF6 GEFs). Together, the results suggest that activation of ARF6 leads to an elevated $\beta 1$ integrin internalization rate.

We next used the same capture ELISA protocol to quantify $\beta 1$ integrin recycling back to the cell surface. This can be done by allowing internalization to occur for 30 min and measuring the quantity of internalized $\beta 1$ integrins as a total internalized pool. In parallel cultures, recycling is allowed to occur at $37^{\circ} \mathrm{C}$ for various periods of time and surface biotin is once again removed at $4^{\circ} \mathrm{C}$. After lysis, the amount of biotinylated integrin remaining in the cells is expressed as a percentage of the total internalized pool so that the amount of recycled integrin can be calculated. We were surprised to find that internalized $\beta 1$ integrins recycled extremely rapidly, and that after $5 \mathrm{~min} \sim 39 \%$ of internalized $\beta 1$ integrins had been recycled in control cells, and that by $10 \mathrm{~min}$ re-internalization was already occurring (Fig. 5B). Overexpression of the inactivating GAP ACAP1 led to a substantial increase in recycling compared with the controls, with $\sim 62 \%$ ( $p<$ 0.05 ) being recycled to the cell surface within $5 \mathrm{~min}$. ACAP1-R448Q also increased
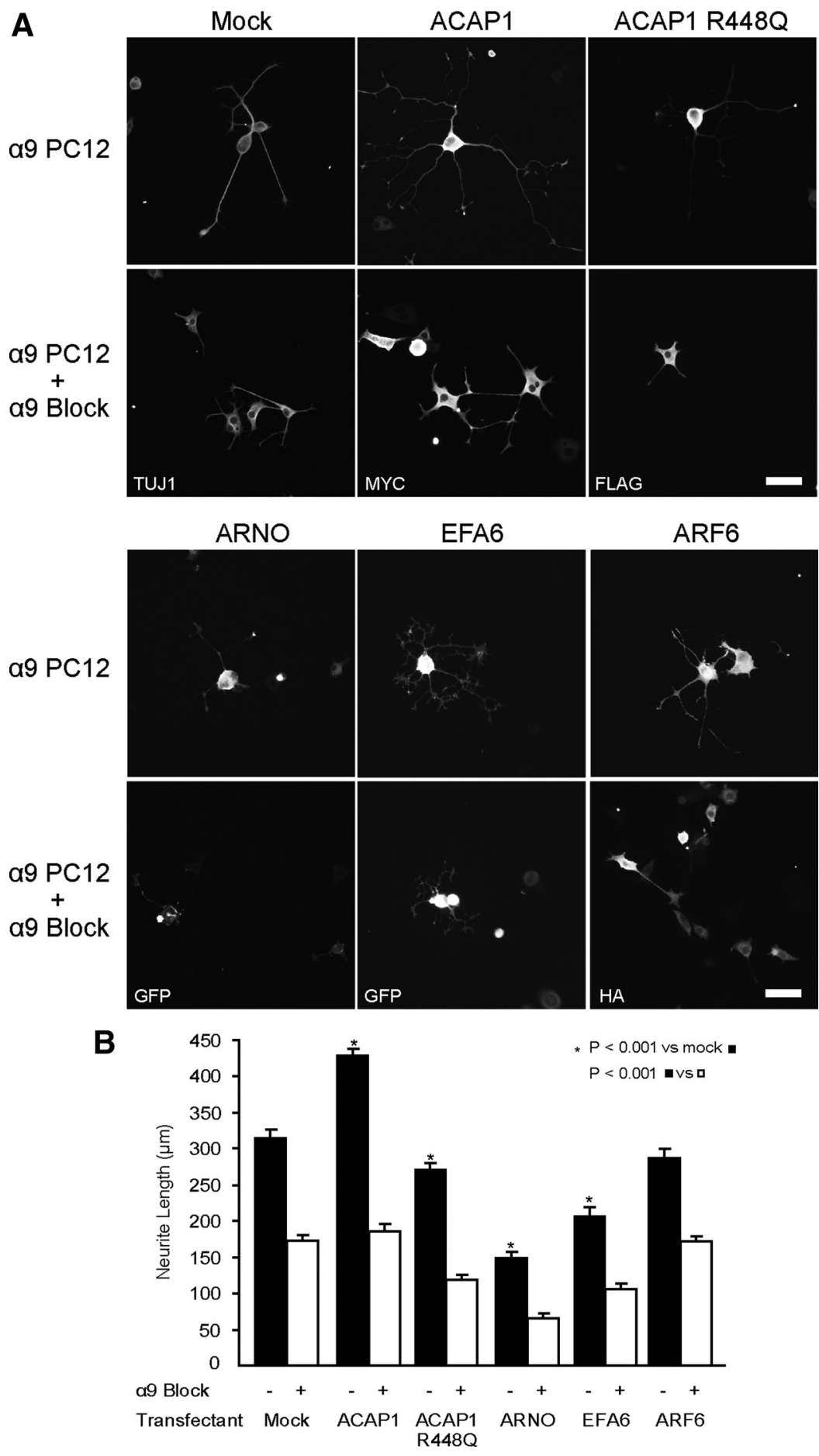

Figure 3. Manipulation of ARF6 regulates $\alpha 9$ integrin-dependent neurite outgrowth on tenascin. Differentiated PC12 cells stably expressing $\alpha 9$ integrin were trypsinized and electroporated with ARF6 regulatory proteins: ARF6 GEFs, either ARN0 or EFA6, an ARF6 GAP, ACAP1, mutant ACAP1 R448Q lacking GAP activity, or wt ARF6 as indicated or mock transfected as a control. These were then grown on a substrate of tenascin for $2 \mathrm{~d}$, in the presence or absence of an $\alpha 9 \beta 1$ blocking antibody (at a concentration that partly inhibits growth), and analyzed for maximum neurite length. Representative images are shown of each condition $(\boldsymbol{A})$. Scale bar, $100 \mu \mathrm{m}$. Overexpression of ACAP1 increases $\alpha$ 9-dependent outgrowth, which is inhibited by anti- $\alpha 9 \beta 1$, whereas ACAP1 R4480 expression inhibits outgrowth, which is inhibited further by anti- $\alpha 9 \beta 1$. Both EFA6 and ARN0 inhibit $\alpha 9$-dependent outgrowth (ARN0 expression results in the most marked effects) and outgrowth is inhibited further by addition of anti- $\alpha 9 \beta 1$. Expression of full-length ARF6 had no effect $(\boldsymbol{B})$. Data were analyzed using ANOVA followed by post hoc analysis. In all cases, blocking with anti- $\alpha 9 \beta 1$ causes statistically significant changes $(p<0.001)$. Error bars indicate SEM. 

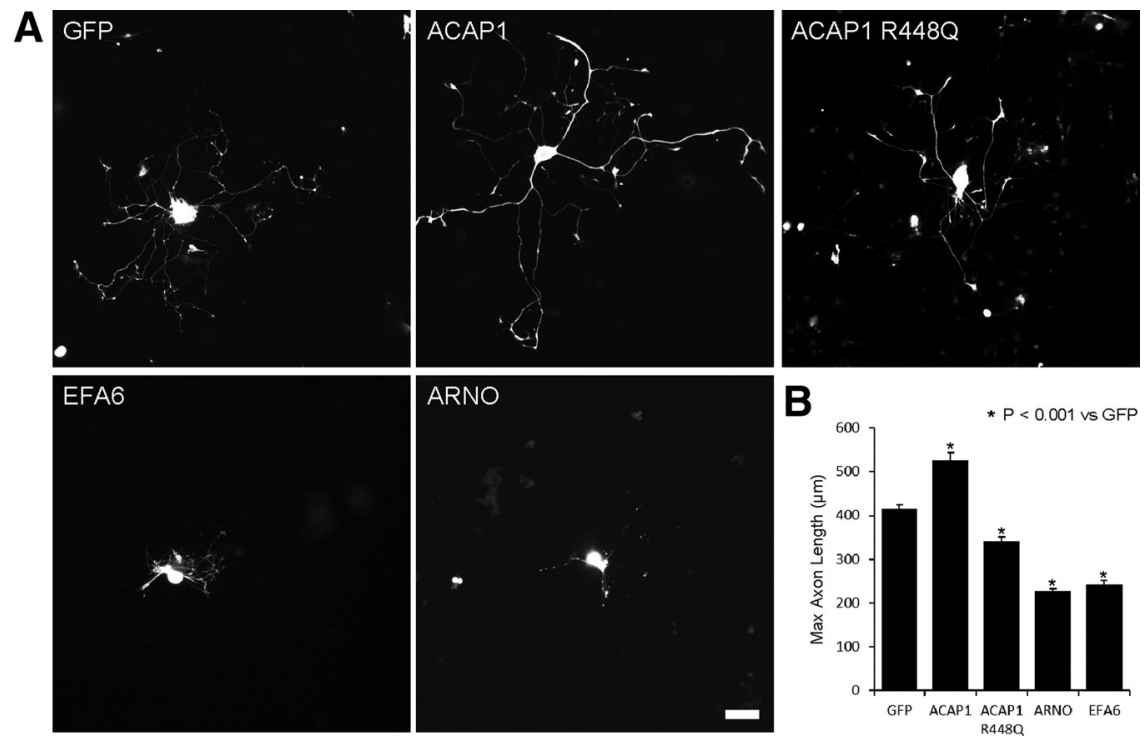

B

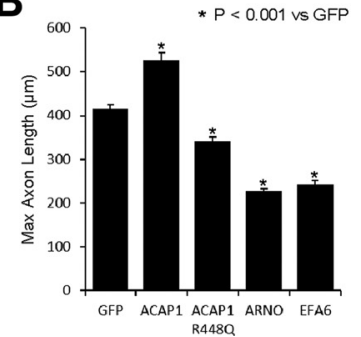

Figure 4. Manipulation of ARF6 affects axon growth in adult DRG neurons. Representative images of DRG neurons expressing ARF6 regulatory proteins as indicated $(\boldsymbol{A})$. Expression of ACAP1 in adult DRG neurons increases axon growth after $2 \mathrm{~d}$ in standard culture conditions, while expression of GAP dead ACAP1 R448Q decreases axon growth. Expression of either EFA6 or ARNO (ARF6 $G E F s)$ leads to a substantial reduction in DRG axon growth $(\boldsymbol{B})$. Data were analyzed by ANOVA with post hoc analysis. $p<0.001$ in all cases, compared with GFP-expressing controls. Scale bar, $100 \mu \mathrm{m}$.

A

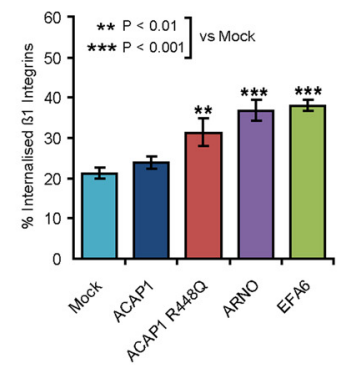

C

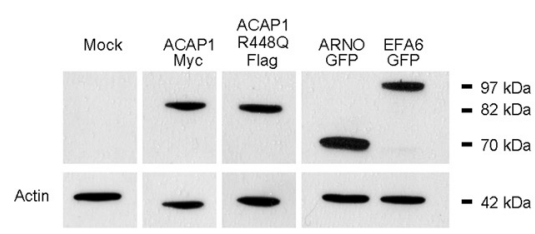

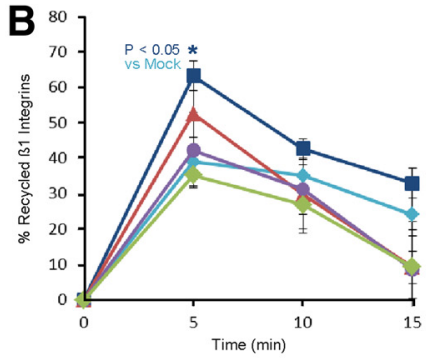

D

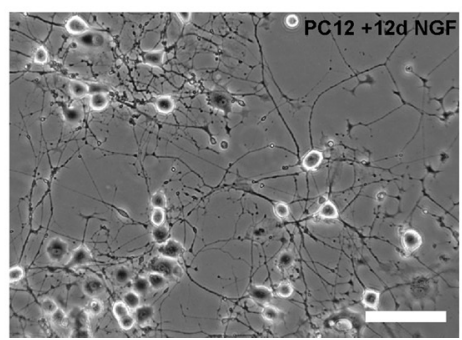

Figure 5. Manipulation of ARF6 activity regulates $\beta 1$ integrin internalization and recycling. $\beta 1$ integrin endocytosis and recycling were measured using a surface biotinylation protocol (described in detail in Materials and Methods) on maturely differentiated PC12 cells transfected with ARF6 regulatory proteins as indicated or mock transfected control cells. Integrin endocytosis was allowed to occur for $30 \mathrm{~min}$, and internalized $\beta 1$ integrin quantified by ELISA. Expression of the ARF6 GEFS ARNO and EFA6 increases $\beta 1$ integrin internalization compared with mock transfected controls, while expression of GAP dead ACAP1 R448Q also increases internalization to a lesser extent. Expression of the ARF6 GAP ACAP1 has no effect $(\boldsymbol{A})$. Integrin endocytosis was once again allowed to occur for $30 \mathrm{~min}$, this time followed by removal of surface integrins, and subsequent incubation to allow recycling to occur for the time points indicated. ACAP1 expression resulted in a significant increase in the rate of $\beta 1$ integrin recycling compared with controls $(p<0.05)$, while ACAP1 R448Q increased recycling to a lesser extent, although this did not achieve significance $(p>0.05)$. Expression of ARN0 and EFA6 had no effect on the rate of recycling, but appeared to increase the rate of internalization of rapidly recycled integrins compared with controls, although again this was not significant $(\boldsymbol{B})$. Transfected cells were lysed and examined by Western blot to check for expression of the transfected constructs $(\boldsymbol{C})$. All extracts were run on the same blot, and then separated for antibody labeling, and reunited for simultaneous developing. $D$ is a representative image of $12 \mathrm{~d}$ differentiated PC12 cells to highlight the neuronal morphology of the cells at the time of experimentation. Scale bar, $100 \mu \mathrm{m}$.

recycling, although not significantly $(53 \%, p>0.05)$, suggesting that ACAP1 is functioning mostly through its ARF GAP activity, but also partly as a coat protein independently of this. In contrast, expression of either of the activating GEFs, EFA6 or ARNO, had no effect on the rate of recycling ( $p>0.05)$; however, there was a nonsignificant increase in the rate at which $\beta 1$ integrins were internalized by 15 $\mathrm{min}$. Together, these data suggest that inactivation of ARF6 increases the rate at which $\beta 1$ integrins are recycled to the cell surface.

Does modulation of ARF6 activity affect axonal transport of $\alpha 9$ integrin?

ARF6 is implicated in the trafficking of membrane proteins in vesicles along microtubules (Caplan et al., 2002; Kanamarlapudi, 2005; Balasubramanian et al., 2007; Montagnac et al., 2009, 2011). It is linked to motor proteins via the scaffold molecules JIP3 and JIP4, and its activation state governs the affinity of the JIP molecules for either kinesin motor proteins or the dynactin/dynein complex, such that ARF6-GTP (activated) interferes with JIP's association with kinesin motors, increasing the affinity of the JIP molecules for the dynactin complex (Isabet et al., 2009; Montagnac et al., 2009, 2011; Suzuki et al., 2010). Given the polarized nature of microtubules in axons (Baas et al., 1988), we hypothesized that activation of ARF6 by overexpression of ARF6 GEFs might lead to increased retrograde transport, while inactivation of ARF6 would favor anterograde transport of integrins. To address this, we used spinning disk confocal microscopy to capture images of $\alpha 9$ integrin-GFP being transported in adult DRG axons coexpressing ARF6 regulatory proteins, and quantified the velocity and direction of $\alpha 9$-GFP vesicles. We used the Cellaxess in-dish electroporator to cotransfect the cells once axon growth was established, and found that $100 \%$ of cells expressing $\alpha 9$-GFP also expressed the cotransfected construct (after fixation and antibody labeling). This allowed us to image $\alpha 9$-GFP assuming the presence in that cell of the unlabeled cotransfectant. All cells were fixed and labeled after the experiments to ensure that the cotransfected construct was expressed (Fig. 6A). To quantify the direction of transport, we classed vesicles as immobile, retrograde, anterograde, or bidirectional. We found that expression of the ARF6 regulatory proteins had no effect on the proportion of mobile and immobile vesicles (Fig. $6 B ; p>0.05$ ), but that they did affect the direction traveled by moving vesicles. Expression of the inactivating GAP ACAP1 increased the proportion of $\alpha 9$-GFP vesicles moving anterograde compared with controls (from 31 to $46 \%$ ), and decreased the retrograde fraction from 35 to $21 \%$ (Fig. 6 C). ACAP1 R448Q again appeared to function as a dominant-negative, and its expression led to a substantial increase in retrograde transport of $\alpha 9$-GFP ( $54 \%$ of the mobile fraction), accompanied by a decrease in antero- 
A
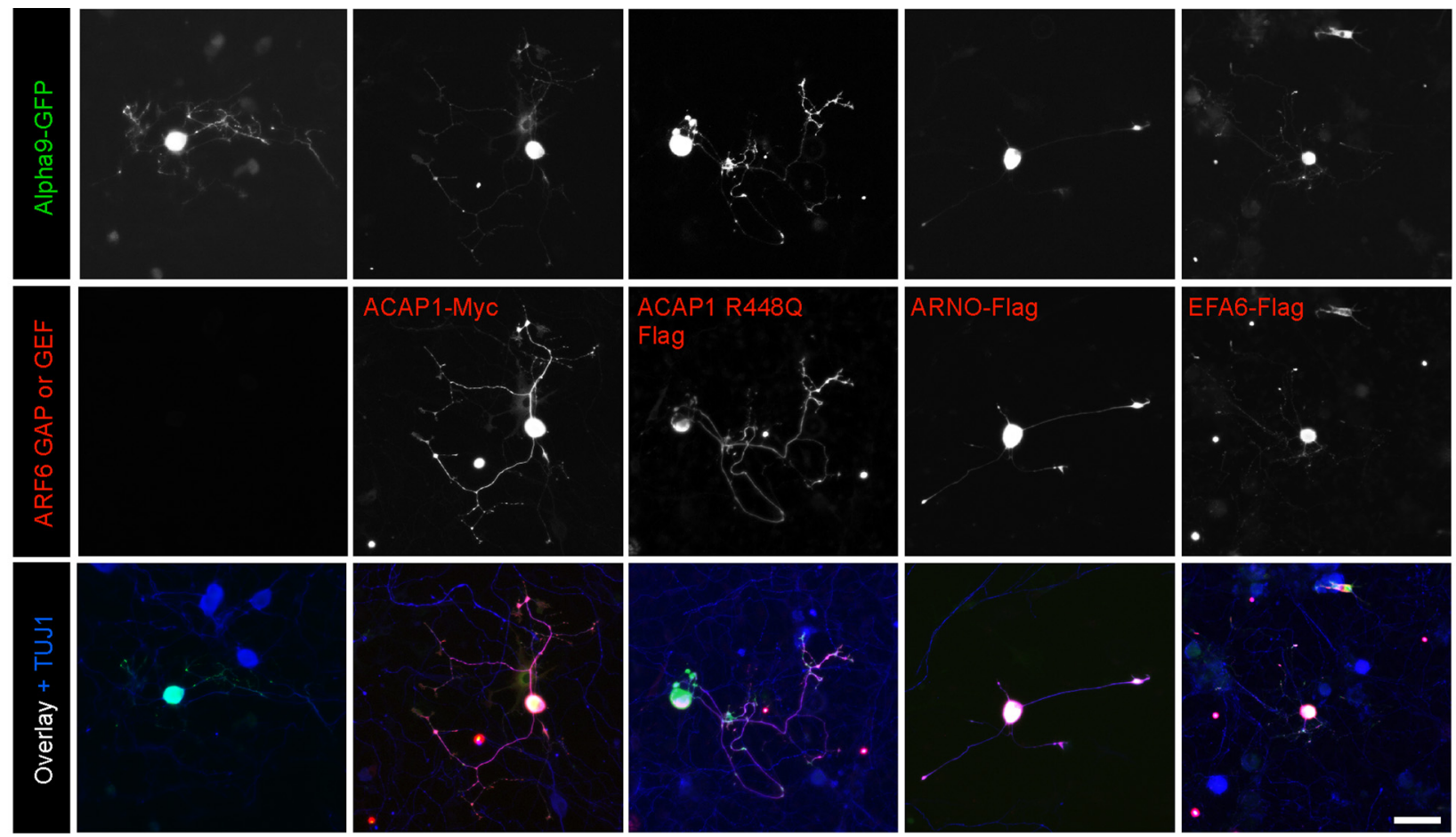

B
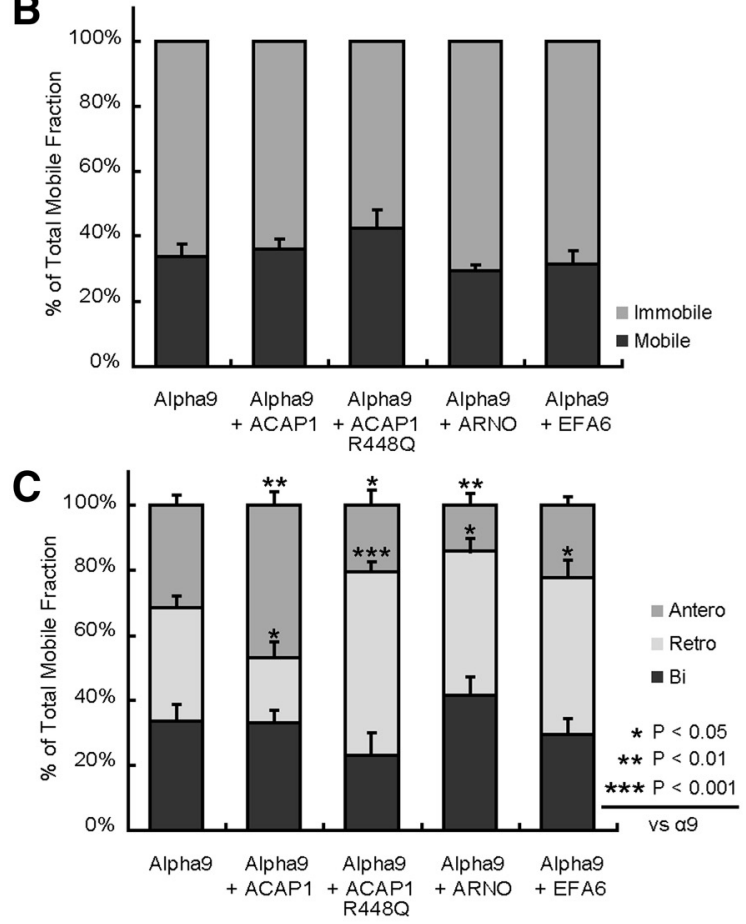

$\mathbf{E}$

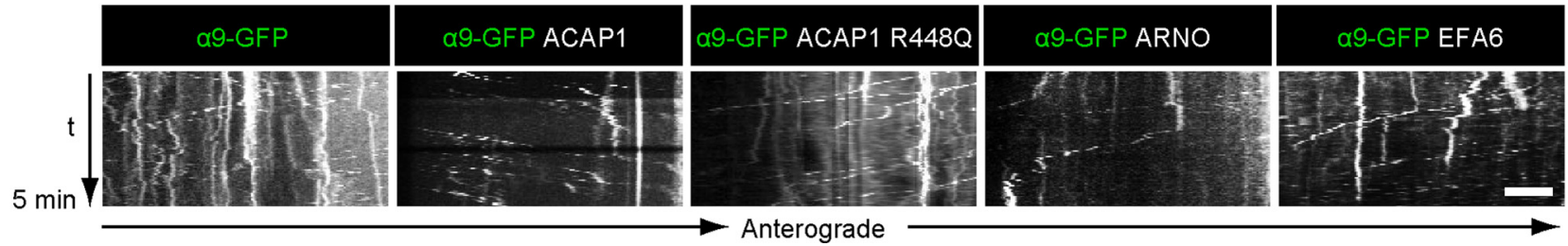

Figure 6. ARF6 manipulation regulates the direction of $\alpha 9$ integrin axonal transport. Spinning disk confocal microscopy was used to image adult DRG neurons expressing $\alpha 9$ integrin-GFP, either alone or cotransfected with epitope-tagged ARF6 regulatory proteins. Cotransfection was confirmed after imaging by fixing and antibody labeling. One hundred percent of cotransfected neurons expressing $\alpha 9$-GFP also expressed their cotransfected partners. Dissociated adult DRG cultures were transfected with $\alpha 9$-GFP alone, and $\alpha 9$-GFP with either ACAP1-myc, ACAP1 R448Q FLAG, ARNO-FLAG, or EFA6-FLAG $(\boldsymbol{A})$. Images of $\alpha 9$-GFP in DRG axons were acquired for $5 \mathrm{~min}$, capturing frames every $3 \mathrm{~s}$. These were used to generate movies and kymographs $(\boldsymbol{E})$. Vesicles were then tracked for their visible lifetime using MetaMorph software and analyzed to quantify direction and velocity. None of the constructs expressed altered the balance between the mobile and immobile fraction of $\alpha 9$-GFP vesicles $(\boldsymbol{B})$; however, differences were seen between the proportion of anterograde and retrograde vesicles within the mobile fraction. Coexpression of (Figure legend continues.) 
grade transport to $23 \%$ (Fig. 6C). Expression of either of the activating GEFs, ARNO or EFA6, also led to an increase in retrograde transport (43 and 48\%, respectively; Fig. $6 C$ ). The proportion of vesicles moving bidirectionally was not changed by any of the molecules (Fig. 6C; $p>0.05$ ). Quantification of the maximum instantaneous velocity or average velocity of moving $\alpha 9$-GFP vesicles showed no statistical difference between any of the groups, although there was a trend for ARNO expression leading to slower anterograde movement and faster retrograde movement compared with control cells (Fig. 6D); the effect of modulating ARF6 function is therefore on the direction of transport rather than its velocity. These data suggest that inactivation of ARF6 increases the anterograde flow of $\alpha 9$-integrins, while activation of ARF6 leads to more retrograde axonal transport, and this is highlighted by representative kymograph images that were generated from movie stack files (Fig. 6E).

\section{Discussion}

We have previously described a strategy to increase axon regeneration after injury via exogenous introduction of $\alpha 9$ integrin, enabling axons to interact with the extracellular matrix glycoprotein tenascin-C, which is upregulated after injury (Andrews et al., 2009). While this strategy works dramatically in vitro, implementing it in vivo has revealed that inhibitory molecules in the CNS inactivate integrins (Tan et al., 2011), and that integrin transport into some CNS axons is limited (J. W. Fawcett and M. R. Andrews, unpublished results). We are therefore investigating strategies for enhancing integrin-dependent axon growth focusing on promoting integrin activation (Tan et al., 2011) and trafficking (Eva et al., 2010). We also believe that a full understanding of successful integrin-mediated axon growth will allow us to identify fundamental defects that prevent regeneration in CNS axons. In our previous trafficking study, we found that much of the $\beta 1$ integrin within axons is in vesicles marked by Rab11. We also demonstrated that Rab11 and its effector Rab coupling protein could be used as tools to enhance integrindependent outgrowth (Eva et al., 2010). Rab11 vesicles exhibited principally localized movement, and when integrins traveled rapidly over larger distances they exited the Rab11 compartment, re-entering it when they ceased rapid transport. This suggests that other molecules are involved in this rapid long-range transport, the manipulation of which might provide strategies for promoting regeneration. A further integrin trafficking pathway regulated by ARF6 has been described in non-neuronal cells (Pellinen and Ivaska, 2006). ARF6-dependent transport is along microtubules, driven by kinesin motors (as opposed to Rab11-dependent trafficking, which is slow and reportedly moves via myosin motors) (Li et al., 2007a; Wang et al., 2008; Eva et al., 2010; Schuh, 2011). The intention of this study was to investigate the hypothesis that integrins might transport rapidly in ARF6 vesicles, and that ARF6 might be involved in integrin trafficking in growth cones. Our

$\leftarrow$

(Figure legend continued.) ACAP1 led to an increase in the proportion of anterograde movement and a decrease in retrograde movement, while ACAP1 R4480 expression had the opposite effect. Expression of EFA6 and ARNO increased retrograde transport and decreased anterograde transport. No statistical changes were found for the bidirectional fraction $(\boldsymbol{C} ; p>0.05)$. Data were analyzed by ANOVA with post hoc analysis. Analysis of instantaneous and average velocity revealed only small differences between groups $(\boldsymbol{D})$. Cumulative frequency distributions were plotted for anterograde ( $\boldsymbol{D}$, left), and retrograde $(\boldsymbol{D}$, right) instantaneous and average velocity, and analyzed using a Kruskal-Wallis test for variance. While no statistical differences were found, there was a trend for ARNO expression leading to slower anterograde transport and faster retrograde transport compared with controls ( $\boldsymbol{D}$; ARNO, purple lines; control, light blue lines). Scale bars: $A, 100 \mu \mathrm{m} ; \boldsymbol{E}, 5 \mu \mathrm{m}$. experiments support this hypothesis. We have established that there is an integrin trafficking pathway in adult DRG axons, additional to the Rab11 pathway that we have already described, that is regulated by ARF6. This pathway is responsible for rapid integrin transport. Importantly, this pathway can be manipulated to enhance integrin-dependent axon growth. Promoting inactivation of ARF6 by expressing an ARF6 GAP increases axon growth, while activation by expression of ARF6 GEFs leads to reduced growth. These changes accompany altered rates of integrin endocytosis and recycling, as well as axon transport, also regulated by the ARF6 activation state.

\section{Integrins traffic via ARF6 in adult DRG axons}

Using ARF6 antibodies as well as mutant ARF6 proteins, we have found that ARF6 is present in adult DRG axons and growth cones, where it is involved in trafficking of $\beta 1$ integrins. Live cell imaging has revealed that integrin in ARF6 vesicles is transported rapidly both anterogradely and retrogradely. This is in addition to the Rab11-dependent trafficking of integrins that we had previously described. ARF6 and Rab11 share certain effector proteins and cooperate during cytokinesis (Hickson et al., 2003; Fielding et al., 2005), and we have now found that the two molecules also cooperate in the axonal trafficking of integrins, with distinctions in the way that vesicles marked by the two proteins traffic. ARF6 marks rapidly moving vesicles, while Rab11 vesicles show small localized movements. We have previously observed fast-moving integrins pausing in Rab11 domains. This could be due to shuttling of integrins between compartments, or swapping of the GTPases on integrin vesicles. This could be governed by localized signaling molecules that regulate the activity of GAP and GEF proteins, such as the PI3 kinase/AKT pathway (Venkateswarlu and Cullen, 2000; Li et al., 2005) or interactions driven by the presence of shared effector molecules (Horgan and McCaffrey, 2009).

The majority of classical axonal transport as driven by kinesin or dynein motors along microtubules travels at a similar speed (1-2 $\mu \mathrm{m} / \mathrm{s}$ ) to ARF6-positive vesicles, and ARF6 is known to traffic along microtubules (Balasubramanian et al., 2007). It has recently come to light that Rab11 contributes to long-range movement via a novel actin-dependent and microtubuleindependent mechanism, reliant on myosin motors (Schuh, 2011). This has yet to be confirmed in axons; however, it will be interesting to determine whether there are two pathways for axonal transport, either by slow actin-based movement or by rapid microtubule-dependent transport.

We have investigated integrin traffic in regenerating adult peripheral sensory axons that have a good regenerative potential. These may differ from mature CNS axons, and it is unclear how ARF6 localizes within mature CNS neurons in vivo. There is evidence that ARF6 influences developing CNS processes because manipulation of the ARF6 GEF, ARNO, results in altered dendritic and axonal morphology of cultured hippocampal neurons (Hernández-Deviez et al., 2004; Hernández-Deviez and Wilson, 2005), and because interfering with the ARF6-JIP3 interaction affects axon length in cortical neurons (Suzuki et al., 2010). Future work will investigate whether there is a trafficking role for ARF6 in mature CNS axons, or whether it is mainly restricted to the somatodendritic compartment. ARF6 is involved in a number of postsynaptic functions within dendritic spines (Choi et al., 2006; Sakagami et al., 2008; Scholz et al., 2010; Fukaya et al., 2011), and is reported to be largely absent from axons of mature hippocampal neurons in culture (Sannerud et al., 2011); however, it is also reported to function presynaptically (Ashery et al., 
1999; Krauss et al., 2003), which might indicate that there is a population of ARF6-positive vesicles trafficking within some adult CNS axons.

\section{ARF6 and integrin-dependent neurite outgrowth}

We have found that ARF6 can be manipulated to enhance integrin-dependent neurite outgrowth. ARF6 has little intrinsic GTPase activity, and is reliant on its GEFs and GAPs for its regulation (Gillingham and Munro, 2007). The level of expression of these ARF6 regulatory proteins impacts integrin-dependent growth in PC12 cells and in DRG neurons, with inactivation of ARF6 by overexpression of a GAP, ACAP1, enhancing outgrowth, while expression of two ARF6-activating GEFs leads to decreased outgrowth. This is in keeping with previous findings in neurons, as expression of either a mutant ARNO that lacks GEF activity or a dominant-negative ARF6 leads to an increase in axon length in hippocampal cultures (Hernández-Deviez et al., 2004), while a mutant p95-APP1 (an ARF6 GAP) lacking the GAP domain inhibits neuritogenesis (Albertinazzi et al., 2003). EFA6 is also reported to oppose axon regeneration in Caenorhabditis elegans, although this may be functioning independently of its ARF GEF activity (Chen et al., 2011).

Interfering with Rab11 also inhibits axon extension (Eva et al., 2010). Correct function of both Rab11 and ARF6 is therefore required for optimal axonal growth, and it is possible that the two molecules may cooperate in regulating it. It will be important to determine whether there is a developmentally regulated mechanism to regulate ARF6 and/or Rab11 in adult CNS axons that might limit integrin-dependent axonal regeneration after injury.

\section{ARF6 and integrin recycling}

ARF6 is involved in $\beta 1$ integrin recycling in non-neuronal cells (Powelka et al., 2004; Dunphy et al., 2006; Yu et al., 2011; Arjonen et al., 2012), and we have now found that $\beta 1$ integrin internalization and recycling back to the cell surface are affected by overexpression of ARF6 regulatory proteins in differentiated PC12 cells. Expressing the ARF6 GEFs, ARNO and EFA6, increases the rate of integrin internalization from the surface, but ACAP1 expression does not oppose this. However, ACAP1 overexpression increases the rate of recycling to the surface, which is unaffected by expression of the two GEFs. ACAP1 functions mainly through its GAP activity to increase the rate of recycling, but also as a coat protein independently of this (as mutating the GAP domain leads to a smaller increase in the rate of recycling). It would therefore appear that activating ARF6 increases the rate of $\beta 1$ integrin internalization, contributing to a decrease in integrin-dependent neurite outgrowth. On the other hand, inactivating ARF6 increases the rate of $\beta 1$ integrin recycling allowing for greater integrin-dependent outgrowth. These results must also be considered in addition to our findings regarding the effects of ARF6 manipulation on the direction of axon transport.

\section{ARF6 and axon transport}

We are particularly interested in understanding how integrin entry to the axon is regulated, as we find that integrins are not transported efficiently into certain adult CNS neurons (Andrews et al., unpublished observations). Our finding in this paper that ARF6 activation can be manipulated to regulate the overall direction of integrin transport within the axon may be relevant to this observation. Expression of EFA6 or ARNO increased retrograde transport while decreasing anterograde transport, and conversely ARF6 inactivation by expression of ACAP1 led to an increase in anterograde transport and a decrease in retrograde movement.
Approximately a third of $\alpha 9$-GFP vesicles move bidirectionally in control axons, and even vesicles with net anterograde or retrograde movement usually show occasional short reverses to the other direction. These direction changes may indicate that ARF6 activation is dynamic, depending on the local preponderance of GAPs and GEFs.

Our results establish a role for ARF6 in the regulation of integrin traffic in peripheral neurons and demonstrate that ARF6 trafficking can be manipulated through ARF6 GAPs and GEFs to regulate the recycling of integrins and the direction of integrin transport within the axon, leading to changes in integrindependent growth. Future experiments will determine whether other molecules involved in axon regeneration are similarly transported, and whether enhanced axon regeneration after injury can be achieved through targeting ARF6.

\section{Notes}

Supplemental material for this article is available at http://www.brc.cam. ac.uk/principal-investigators/james-fawcett/recent-papers/. This material has not been peer reviewed.

\section{References}

Aikawa Y, Martin TF (2003) ARF6 regulates a plasma membrane pool of phosphatidylinositol $(4,5)$ bisphosphate required for regulated exocytosis. J Cell Biol 162:647-659.

Albertinazzi C, Za L, Paris S, de Curtis I (2003) ADP-ribosylation factor 6 and a functional PIX/p95-APP1 complex are required for Rac1Bmediated neurite outgrowth. Mol Biol Cell 14:1295-1307.

Andrews MR, Czvitkovich S, Dassie E, Vogelaar CF, Faissner A, Blits B, Gage FH, ffrench-Constant C, Fawcett JW (2009) Alpha9 integrin promotes neurite outgrowth on tenascin- $\mathrm{C}$ and enhances sensory axon regeneration. J Neurosci 29:5546-5557.

Arjonen A, Alanko J, Veltel S, Ivaska J (2012) Distinct recycling of active and inactive betal integrins. Traffic 13:610-625.

Ashery U, Koch H, Scheuss V, Brose N, Rettig J (1999) A presynaptic role for the ADP ribosylation factor (ARF)-specific GDP/GTP exchange factor msec7-1. Proc Natl Acad Sci U S A 96:1094-1099.

Baas PW, Deitch JS, Black MM, Banker GA (1988) Polarity orientation of microtubules in hippocampal neurons: uniformity in the axon and nonuniformity in the dendrite. Proc Natl Acad Sci U S A 85:8335-8339.

Balasubramanian N, Scott DW, Castle JD, Casanova JE, Schwartz MA (2007) Arf6 and microtubules in adhesion-dependent trafficking of lipid rafts. Nat Cell Biol 9:1381-1391.

Barral DC, Cavallari M, McCormick PJ, Garg S, Magee AI, Bonifacino JS, De Libero G, Brenner MB (2008) CD1a and MHC class I follow a similar endocytic recycling pathway. Traffic 9:1446-1457.

Brakebusch C, Fässler R (2005) beta 1 integrin function in vivo: adhesion, migration and more. Cancer Metastasis Rev 24:403-411.

Brown FD, Rozelle AL, Yin HL, Balla T, Donaldson JG (2001) Phosphatidylinositol 4,5-bisphosphate and Arf6-regulated membrane traffic. J Cell Biol 154:1007-1017.

Caplan S, Naslavsky N, Hartnell LM, Lodge R, Polishchuk RS, Donaldson JG, Bonifacino JS (2002) A tubular EHD1-containing compartment involved in the recycling of major histocompatibility complex class I molecules to the plasma membrane. EMBO J 21:2557-2567.

Chen L, Wang Z, Ghosh-Roy A, Hubert T, Yan D, O’Rourke S, Bowerman B, Wu Z, Jin Y, Chisholm AD (2011) Axon regeneration pathways identified by systematic genetic screening in C. elegans. Neuron 71:1043-1057.

Choi S, Ko J, Lee JR, Lee HW, Kim K, Chung HS, Kim H, Kim E (2006) ARF6 and EFA6A regulate the development and maintenance of dendritic spines. J Neurosci 26:4811-4819.

Dai J, Li J, Bos E, Porcionatto M, Premont RT, Bourgoin S, Peters PJ, Hsu VW (2004) ACAP1 promotes endocytic recycling by recognizing recycling sorting signals. Dev Cell 7:771-776.

Donaldson JG (2003) Multiple roles for Arf6: sorting, structuring, and signaling at the plasma membrane. J Biol Chem 278:41573-41576.

Dunphy JL, Moravec R, Ly K, Lasell TK, Melancon P, Casanova JE (2006) The Arf6 GEF GEP100/BRAG2 regulates cell adhesion by controlling endocytosis of betal integrins. Curr Biol 16:315-320.

Eva R, Dassie E, Caswell PT, Dick G, ffrench-Constant C, Norman JC, Fawcett 
JW (2010) Rab11 and its effector Rab coupling protein contribute to the trafficking of beta 1 integrins during axon growth in adult dorsal root ganglion neurons and PC12 cells. J Neurosci 30:11654-11669.

Fielding AB, Schonteich E, Matheson J, Wilson G, Yu X, Hickson GR, Srivastava S, Baldwin SA, Prekeris R, Gould GW (2005) Rab11-FIP3 and FIP4 interact with Arf6 and the exocyst to control membrane traffic in cytokinesis. EMBO J 24:3389-3399.

Franco M, Peters PJ, Boretto J, van Donselaar E, Neri A, D’Souza-Schorey C, Chavrier P (1999) EFA6, a sec7 domain-containing exchange factor for ARF6, coordinates membrane recycling and actin cytoskeleton organization. EMBO J 18:1480-1491.

Frank S, Upender S, Hansen SH, Casanova JE (1998) ARNO is a guanine nucleotide exchange factor for ADP-ribosylation factor 6. J Biol Chem 273:23-27.

Fukaya M, Kamata A, Hara Y, Tamaki H, Katsumata O, Ito N, Takeda S, Hata Y, Suzuki T, Watanabe M, Harvey RJ, Sakagami H (2011) SynArfGEF is a guanine nucleotide exchange factor for Arf6 and localizes preferentially at post-synaptic specializations of inhibitory synapses. J Neurochem 116:1122-1137.

Furman C, Short SM, Subramanian RR, Zetter BR, Roberts TM (2002) DEF-1/ASAP1 is a GTPase-activating protein (GAP) for ARF1 that enhances cell motility through a GAP-dependent mechanism. J Biol Chem 277:7962-7969.

Gardiner NJ, Fernyhough P, Tomlinson DR, Mayer U, von der Mark H, Streuli CH (2005) Alpha7 integrin mediates neurite outgrowth of distinct populations of adult sensory neurons. Mol Cell Neurosci 28:229-240.

Gardiner NJ, Moffatt S, Fernyhough P, Humphries MJ, Streuli CH, Tomlinson DR (2007) Preconditioning injury-induced neurite outgrowth of adult rat sensory neurons on fibronectin is mediated by mobilisation of axonal alpha5 integrin. Mol Cell Neurosci 35:249-260.

Gillingham AK, Munro S (2007) The small G proteins of the Arf family and their regulators. Annu Rev Cell Dev Biol 23:579-611.

Gong Q, Weide M, Huntsman C, Xu Z, Jan LY, Ma D (2007) Identification and characterization of a new class of trafficking motifs for controlling clathrin-independent internalization and recycling. J Biol Chem 282:13087-13097.

Hall B, McLean MA, Davis K, Casanova JE, Sligar SG, Schwartz MA (2008) A fluorescence resonance energy transfer activation sensor for Arf6. Anal Biochem 374:243-249.

Hernández-Deviez DJ, Wilson JM (2005) Functional assay of ARNO and ARF6 in neurite elongation and branching. Methods Enzymol 404:242-252.

Hernández-Deviez DJ, Casanova JE, Wilson JM (2002) Regulation of dendritic development by the ARF exchange factor ARNO. Nat Neurosci 5:623-624.

Hernández-Deviez DJ, Roth MG, Casanova JE, Wilson JM (2004) ARNO and ARF6 regulate axonal elongation and branching through downstream activation of phosphatidylinositol 4-phosphate 5-kinase alpha. Mol Biol Cell 15:111-120.

Hernández-Deviez D, Mackay-Sim A, Wilson JM (2007) A Role for ARF6 and ARNO in the regulation of endosomal dynamics in neurons. Traffic 8:1750-1764.

Hickson GR, Matheson J, Riggs B, Maier VH, Fielding AB, Prekeris R, Sullivan W, Barr FA, Gould GW (2003) Arfophilins are dual Arf/Rab 11 binding proteins that regulate recycling endosome distribution and are related to Drosophila nuclear fallout. Mol Biol Cell 14:2908-2920.

Hofmann I, Thompson A, Sanderson CM, Munro S (2007) The Arl4 family of small $\mathrm{G}$ proteins can recruit the cytohesin Arf6 exchange factors to the plasma membrane. Curr Biol 17:711-716.

Horgan CP, McCaffrey MW (2009) The dynamic Rab11-FIPs. Biochem Soc Trans 37:1032-1036.

Inoue H, Ha VL, Prekeris R, Randazzo PA (2008) Arf GTPase-activating protein ASAP1 interacts with Rab11 effector FIP3 and regulates pericentrosomal localization of transferrin receptor-positive recycling endosome. Mol Biol Cell 19:4224-4237.

Isabet T, Montagnac G, Regazzoni K, Raynal B, El Khadali F, England P, Franco M, Chavrier P, Houdusse A, Ménétrey J (2009) The structural basis of Arf effector specificity: the crystal structure of ARF6 in a complex with JIP4. EMBO J 28:2835-2845.

Jackson TR, Brown FD, Nie Z, Miura K, Foroni L, Sun J, Hsu VW, Donaldson
JG, Randazzo PA (2000) ACAPs are arf6 GTPase-activating proteins that function in the cell periphery. J Cell Biol 151:627-638.

Kanamarlapudi V (2005) Centaurin-alphal and KIF13B kinesin motor protein interaction in ARF6 signalling. Biochem Soc Trans 33:1279-1281.

Krauss M, Kinuta M, Wenk MR, De Camilli P, Takei K, Haucke V (2003) ARF6 stimulates clathrin/AP-2 recruitment to synaptic membranes by activating phosphatidylinositol phosphate kinase type Igamma. J Cell Biol 162:113-124.

Lavezzari G, Roche KW (2007) Constitutive endocytosis of the metabotropic glutamate receptor mGluR7 is clathrin-independent. Neuropharmacology 52:100-107.

Li BX, Satoh AK, Ready DF (2007a) Myosin V, Rab11, and dRip11 direct apical secretion and cellular morphogenesis in developing Drosophila photoreceptors. J Cell Biol 177:659-669.

Li J, Ballif BA, Powelka AM, Dai J, Gygi SP, Hsu VW (2005) Phosphorylation of ACAP1 by Akt regulates the stimulation-dependent recycling of integrin beta1 to control cell migration. Dev Cell 9:663-673.

Li J, Peters PJ, Bai M, Dai J, Bos E, Kirchhausen T, Kandror KV, Hsu VW (2007b) An ACAP1-containing clathrin coat complex for endocytic recycling. J Cell Biol 178:453-464.

Lin CY, Hilgenberg LG, Smith MA, Lynch G, Gall CM (2008) Integrin regulation of cytoplasmic calcium in excitatory neurons depends upon glutamate receptors and release from intracellular stores. Mol Cell Neurosci 37:770-780.

Macia E, Chabre M, Franco M (2001) Specificities for the small G proteins ARF1 and ARF6 of the guanine nucleotide exchange factors ARNO and EFA6. J Biol Chem 276:24925-24930.

McGeachie AB, Cingolani LA, Goda Y (2011) A stabilising influence: Integrins in regulation of synaptic plasticity. Neurosci Res 70:24-29.

Miyazaki H, Yamazaki M, Watanabe H, Maehama T, Yokozeki T, Kanaho Y (2005) The small GTPase ADP-ribosylation factor 6 negatively regulates dendritic spine formation. FEBS Lett 579:6834-6838.

Montagnac G, Sibarita JB, Loubéry S, Daviet L, Romao M, Raposo G, Chavrier P (2009) ARF6 Interacts with JIP4 to control a motor switch mechanism regulating endosome traffic in cytokinesis. Curr Biol 19:184-195.

Montagnac G, de Forges H, Smythe E, Gueudry C, Romao M, Salamero J, Chavrier P (2011) Decoupling of activation and effector binding underlies ARF6 priming of fast endocytic recycling. Curr Biol 21:574-579.

Myers JP, Gomez TM (2011) Focal adhesion kinase promotes integrin adhesion dynamics necessary for chemotropic turning of nerve growth cones. J Neurosci 31:13585-13595.

Naslavsky N, Weigert R, Donaldson JG (2003) Convergence of nonclathrin- and clathrin-derived endosomes involves Arf6 inactivation and changes in phosphoinositides. Mol Biol Cell 14:417-431.

Naslavsky N, Weigert R, Donaldson JG (2004) Characterization of a nonclathrin endocytic pathway: membrane cargo and lipid requirements. Mol Biol Cell 15:3542-3552.

Pellinen T, Ivaska J (2006) Integrin traffic. J Cell Sci 119:3723-3731.

Pellinen T, Arjonen A, Vuoriluoto K, Kallio K, Fransen JA, Ivaska J (2006) Small GTPase Rab21 regulates cell adhesion and controls endosomal traffic of beta1-integrins. J Cell Biol 173:767-780.

Peters PJ, Hsu VW, Ooi CE, Finazzi D, Teal SB, Oorschot V, Donaldson JG, Klausner RD (1995) Overexpression of wild-type and mutant ARF1 and ARF6: distinct perturbations of nonoverlapping membrane compartments. J Cell Biol 128:1003-1017.

Plantman S, Patarroyo M, Fried K, Domogatskaya A, Tryggvason K, Hammarberg H, Cullheim S (2008) Integrin-laminin interactions controlling neurite outgrowth from adult DRG neurons in vitro. Mol Cell Neurosci 39:50-62.

Powelka AM, Sun J, Li J, Gao M, Shaw LM, Sonnenberg A, Hsu VW (2004) Stimulation-dependent recycling of integrin betal regulated by ARF6 and Rab11. Traffic 5:20-36.

Radhakrishna H, Klausner RD, Donaldson JG (1996) Aluminum fluoride stimulates surface protrusions in cells overexpressing the ARF6 GTPase. J Cell Biol 134:935-947.

Roberts M, Barry S, Woods A, van der Sluijs P, Norman J (2001) PDGFregulated rab4-dependent recycling of alphavbeta3 integrin from early endosomes is necessary for cell adhesion and spreading. Curr Biol 11:1392-1402.

Sakagami H (2008) The EFA6 family: guanine nucleotide exchange factors 
for ADP ribosylation factor 6 at neuronal synapses. Tohoku J Exp Med 214:191-198.

Sakagami H, Sanda M, Fukaya M, Miyazaki T, Sukegawa J, Yanagisawa T, Suzuki T, Fukunaga K, Watanabe M, Kondo H (2008) IQ-ArfGEF/ BRAG1 is a guanine nucleotide exchange factor for Arf6 that interacts with PSD-95 at postsynaptic density of excitatory synapses. Neurosci Res 60:199-212.

Sannerud R, Declerck I, Peric A, Raemaekers T, Menendez G, Zhou L, Veerle B, Coen K, Munck S, De Strooper B, Schiavo G, Annaert W (2011) ADP ribosylation factor 6 (ARF6) controls amyloid precursor protein (APP) processing by mediating the endosomal sorting of BACE1. Proc Natl Acad Sci U S A 108:E559-568.

Scholz R, Berberich S, Rathgeber L, Kolleker A, Köhr G, Kornau HC (2010) AMPA receptor signaling through BRAG2 and Arf6 critical for long-term synaptic depression. Neuron 66:768-780.

Schuh M (2011) An actin-dependent mechanism for long-range vesicle transport. Nat Cell Biol 13:1431-1436.

Suzuki A, Arikawa C, Kuwahara Y, Itoh K, Watanabe M, Watanabe H, Suzuki T, Funakoshi Y, Hasegawa H, Kanaho Y (2010) The scaffold protein JIP3 functions as a downstream effector of the small GTPase ARF6 to regulate neurite morphogenesis of cortical neurons. FEBS Lett 584:2801-2806.

Tan CL, Kwok JC, Patani R, Ffrench-Constant C, Chandran S, Fawcett JW (2011) Integrin activation promotes axon growth on inhibitory chondroitin sulfate proteoglycans by enhancing integrin signaling. J Neurosci 31:6289-6295.

Tang X, Davies JE, Davies SJ (2003) Changes in distribution, cell associa- tions, and protein expression levels of NG2, neurocan, phosphacan, brevican, versican V2, and tenascin-C during acute to chronic maturation of spinal cord scar tissue. J Neurosci Res 71:427-444.

Venkateswarlu K (2003) Interaction protein for cytohesin exchange factors 1 (IPCEF1) binds cytohesin 2 and modifies its activity. J Biol Chem 278:43460-43469.

Venkateswarlu K, Cullen PJ (2000) Signalling via ADP-ribosylation factor 6 lies downstream of phosphatidylinositide 3-kinase. Biochem J $345 \mathrm{Pt}$ 3:719-724.

Venkateswarlu K, Oatey PB, Tavaré JM, Cullen PJ (1998) Insulindependent translocation of ARNO to the plasma membrane of adipocytes requires phosphatidylinositol 3-kinase. Curr Biol 8:463-466.

Wang Z, Edwards JG, Riley N, Provance DW Jr, Karcher R, Li XD, Davison IG, Ikebe M, Mercer JA, Kauer JA, Ehlers MD (2008) Myosin Vb mobilizes recycling endosomes and AMPA receptors for postsynaptic plasticity. Cell 135:535-548.

Webb DJ, Zhang H, Majumdar D, Horwitz AF (2007) alpha5 integrin signaling regulates the formation of spines and synapses in hippocampal neurons. J Biol Chem 282:6929-6935.

Werner A, Willem M, Jones LL, Kreutzberg GW, Mayer U, Raivich G (2000) Impaired axonal regeneration in alpha7 integrin-deficient mice. J Neurosci 20:1822-1830.

Yu X, Wang F, Liu H, Adams G, Aikhionbare F, Liu D, Cao X, Fan L, Hu G, Chen Y, Frost A, Partridge E, Ding X, Yao X (2011) ACAP4 protein cooperates with Grb2 protein to orchestrate epidermal growth factorstimulated integrin betal recycling in cell migration. J Biol Chem 286: $43735-43747$. 